\title{
E-Selective Semi-Hydrogenation of Alkynes by Heterobimetallic Catalysis
}

Malkanthi K. Karunananda and Neal P. Mankad*

\author{
Department of Chemistry, University of Illinois at Chicago, Chicago, IL 60642, USA. \\ *E-mail: npm@uic.edu
}

\section{Electronic Supplementary Information}

\section{Table of contents}

$\begin{array}{ll}\text { General considerations } & \text { S2 }\end{array}$

$\begin{array}{ll}\text { Physical measurements } & \text { S2 }\end{array}$

$\begin{array}{ll}\text { Computational methods } & \text { S2 }\end{array}$

$\begin{array}{ll}\text { Synthesis of catalysts } & \text { S3 }\end{array}$

$\begin{array}{ll}\text { General procedure for catalyst optimization } & \text { S9 }\end{array}$

General procedure for catalytic semi-hydrogenation of alkynes by (IMes)AgRp $\quad$ S14

$\begin{array}{ll}\text { General procedure for the alkene isomerization } & \text { S18 }\end{array}$

$\begin{array}{ll}\text { Procedure for the control of the alkene isomerization } & \text { S21 }\end{array}$

$\begin{array}{ll}\text { General procedure for the robustness screen using additives } & \text { S22 }\end{array}$ 


\section{General considerations}

Unless otherwise specified, all reactions and manipulations were performed under purified $\mathrm{N}_{2}$ in a glovebox or using standard Schlenk line techniques. Glassware was oven-dried prior to use. Reaction solvents were sparged with argon and dried using a Glass Contour Solvent System built by Pure Process Technology, LLC (toluene, pentane), or purified by repeated freeze-pump-thaw cycles followed by prolonged storage over activated, 3- $\AA$ molecular sieves (xylenes, NMR solvents). $\mathrm{H}_{2}$ gas was purchased from PRAXAIR at a purity of 99.999\% (5.0 UHP grade) and purified further by running through an $\mathrm{O}_{2}$ removing catalyst column (RCI GetterMax 133T) and a drying column (Drierite). Literature methods were used to synthesize $\mathrm{Rp}_{2},{ }^{1}$ IPrAgOAc, ${ }^{2}$ (IMes)AgCl, (IPr)AgCl, ${ }^{3} \mathrm{KFp},{ }^{4} \mathrm{NaRp}$, (IMes)CuFp, (IPr)CuFp, (IMes)CuRp, (IPr)CuRp, and (IPr)AgRp. ${ }^{5}$ Unless otherwise specified, all chemicals were purchased from commercial sources and used without further purification.

\section{Physical measurements}

NMR spectra were recorded at ambient temperature using Bruker Avance DPX-400 and Bruker Avance DRX-500 spectrometers. ${ }^{1} \mathrm{H}$ NMR and ${ }^{13} \mathrm{C}\left\{{ }^{1} \mathrm{H}\right\}$ NMR chemical shifts were referenced to residual solvent peaks. FT-IR spectra were recorded on solid samples in a glovebox using a Bruker ALPHA spectrometer fitted with a diamond-ATR detection unit. Elemental analyses were performed by Midwest Microlab, LLC in Indianapolis, IN. Single-crystal X-ray diffraction studies were performed using a Bruker SMART $\mathrm{X} 2 \mathrm{~S}$ benchtop diffractometer fitted with an Oxford Cryostreams desktop cooler. Solution and refinement were accomplished with the SHELXTL suite of programs, ${ }^{6}$ using standard methods, ${ }^{7}$ and CIF files are included as Supporting Information.

\section{Computational methods}

Optimized data for $(\mathrm{IMe}) \mathrm{Cu}-[\mathrm{M}]$ complexes (where $[\mathrm{M}]=\mathrm{FeCp}(\mathrm{CO})_{2}, \mathrm{RuCp}(\mathrm{CO})_{2}, \mathrm{WCp}(\mathrm{CO})_{3}$, $\left.\left.\mathrm{Mn}(\mathrm{CO})_{5}, \mathrm{MoCp}(\mathrm{CO})_{3}, \mathrm{CrCp}(\mathrm{CO})_{3}, \mathrm{CrCp}(\mathrm{CO})_{3}, \mathrm{Co}(\mathrm{CO})_{4}\right)\right)$ were obtained from literature., ${ }^{5,8}$ All calculations were performed using Gaussian09, Revision B.01. ${ }^{9}$ Density functional theory (DFT) calculations were carried out using a hybrid functional, BVP86, consisting of Becke's 1988 gradientcorrected Slater exchange functional ${ }^{10}$ combined with the VWNS local electron correlation functional and Perdew's 1986 nonlocal electron correlation functional. ${ }^{11}$ Mixed basis sets were employed: the LANL2TZ(f) triple- $\zeta$ basis set ${ }^{12,13,14}$ with effective core potential ${ }^{12,15,16}$ was used for $\mathrm{Cr}, \mathrm{Mn}, \mathrm{Fe}, \mathrm{Co}, \mathrm{Cu}$, $\mathrm{Mo}, \mathrm{Ru}, \mathrm{Ag}, \mathrm{W}$ and Re; and the Gaussian09 internal 6-311+G(d) basis set was used for $\mathrm{C}, \mathrm{H}$, N, and $\mathrm{O}$. The 2,4,6-trimethylphenyl groups on the NHC ligands were truncated to methyl groups in order to minimize computational time. Vibrational frequency analysis confirmed that all stationary points were correctly identified either as stable intermediates with zero imaginary frequencies or transition states with only one imaginary frequency. The sum of electronic and thermal free energies were used to calculate the $\Delta G$ values at $298 \mathrm{~K}$. Intrinsic reaction coordinate calculations confirmed that the transition state was situated between its corresponding reactant and product states on the Born-Oppenheimer potential energy surface. 


\section{Synthesis of catalysts}

\section{(IMes)Ag-Rp.}

(IMes) $\mathrm{AgCl}(0.1004 \mathrm{~g}, 0.224 \mathrm{mmol}, 1$ equiv) was dissolved in toluene $(10 \mathrm{~mL})$, and $\mathrm{NaRp}(0.1100 \mathrm{~g}$, $0.448 \mathrm{mmol}, 2$ equiv) was added to the solution. The brown solution was stirred for $24 \mathrm{~h}$ at room temperature. The solution was filtered through Celite, and the filtrate was evaporated to dryness. The remaining solid was suspended in pentane $(10 \mathrm{~mL})$ and stirred vigorously for $30 \mathrm{~min}$. The suspension was filtered through a fritted glass filter, and the brown-yellow solid was washed with pentane $(3 \times 5 \mathrm{~mL})$ and then dried in vacuo. Yield: $0.1052 \mathrm{~g}, 0.165 \mathrm{mmol}, 74 \%$. The solid was stored in a glovebox freezer at -36 ${ }^{\circ} \mathrm{C}$. X-ray quality crystals were grown by vapor diffusion of pentane into a concentrated toluene solution at $-36{ }^{\circ} \mathrm{C} .{ }^{1} \mathrm{H}$ NMR $\left(400 \mathrm{MHz}, \mathrm{C}_{6} \mathrm{D}_{6}\right): \delta 6.76(\mathrm{~s}, 4 \mathrm{H}, \mathrm{m}-\mathrm{H}), 6.05(\mathrm{~s}, 2 \mathrm{H}, \mathrm{NCH}), 4.80$ (s, Cp), $2.08(\mathrm{~s}, 6 \mathrm{H}$, p- $\left.\mathrm{CH}_{3}\right), 2.03\left(\mathrm{~s}, 12 \mathrm{H}, \mathrm{o}-\mathrm{CH}_{3}\right) .{ }^{13} \mathrm{C}\left\{{ }^{1} \mathrm{H}\right\}$ NMR $\left(125 \mathrm{MHz}, \mathrm{C}_{6} \mathrm{D}_{6}\right): \delta 209.1(\mathrm{CO}), 139.1,135.8,134.7,129.3$, 121.0, 80.1 (Cp), 20.7, 17.5. Note: Even after 10000 scans on a near-saturated solution, the ${ }^{13} \mathrm{C}$ signal for the carbene carbon was not detected. IR (solid, $\mathrm{cm}^{-1}$ ): 1930 (vCO), 1864 (vCO), 788, 566. Anal. Calcd for $\mathrm{C}_{28} \mathrm{H}_{29} \mathrm{~N}_{2} \mathrm{O}_{2} \mathrm{AgRu}$ : C, 53.00; H, 4.61; N, 4.42. Found: C, 52.97; H, 4.49; N, 4.46.

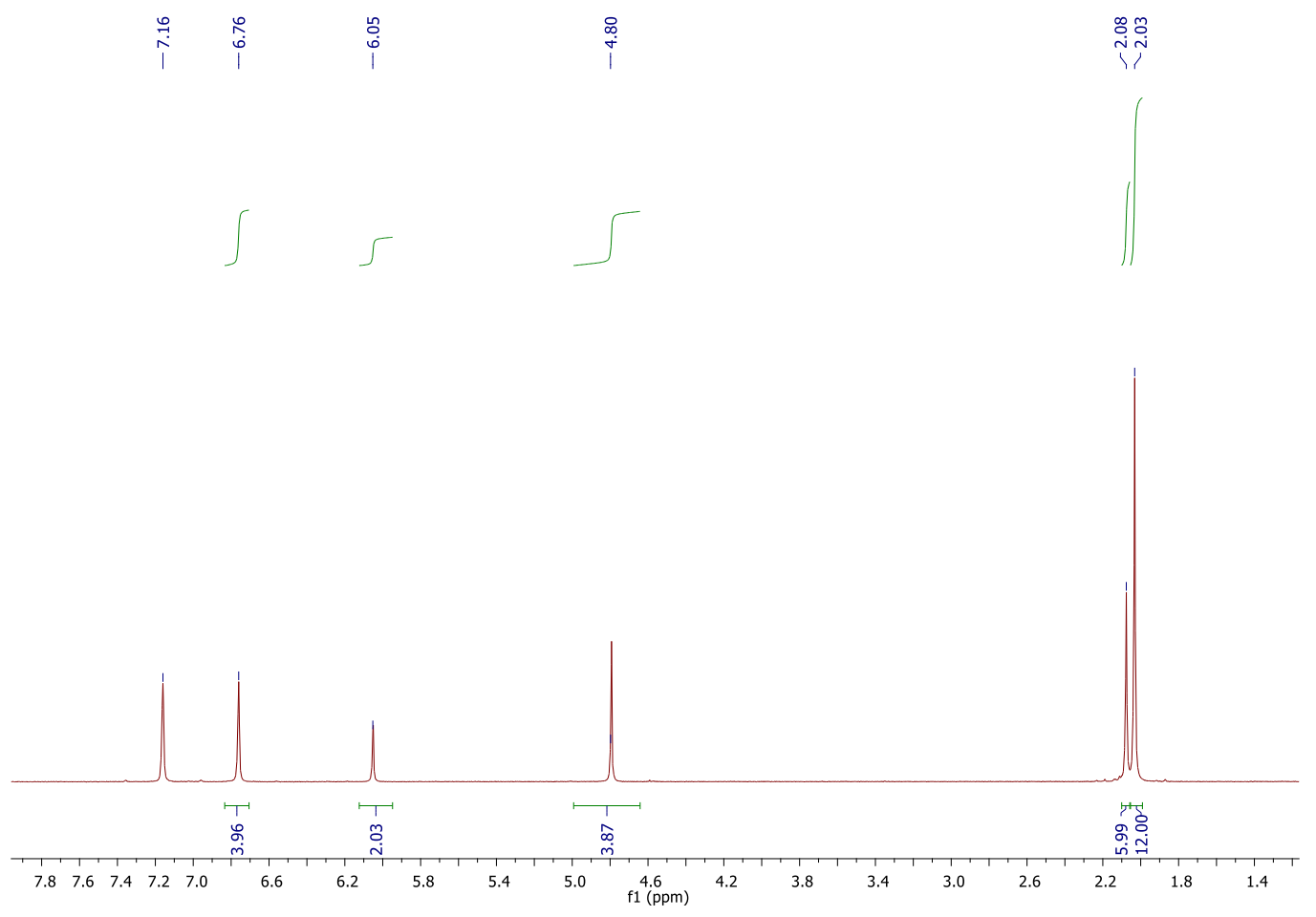

Figure $\mathrm{S} 1:{ }^{1} \mathrm{H}$ NMR spectrum of (IMes)AgRp in $\mathrm{C}_{6} \mathrm{D}_{6}$ 


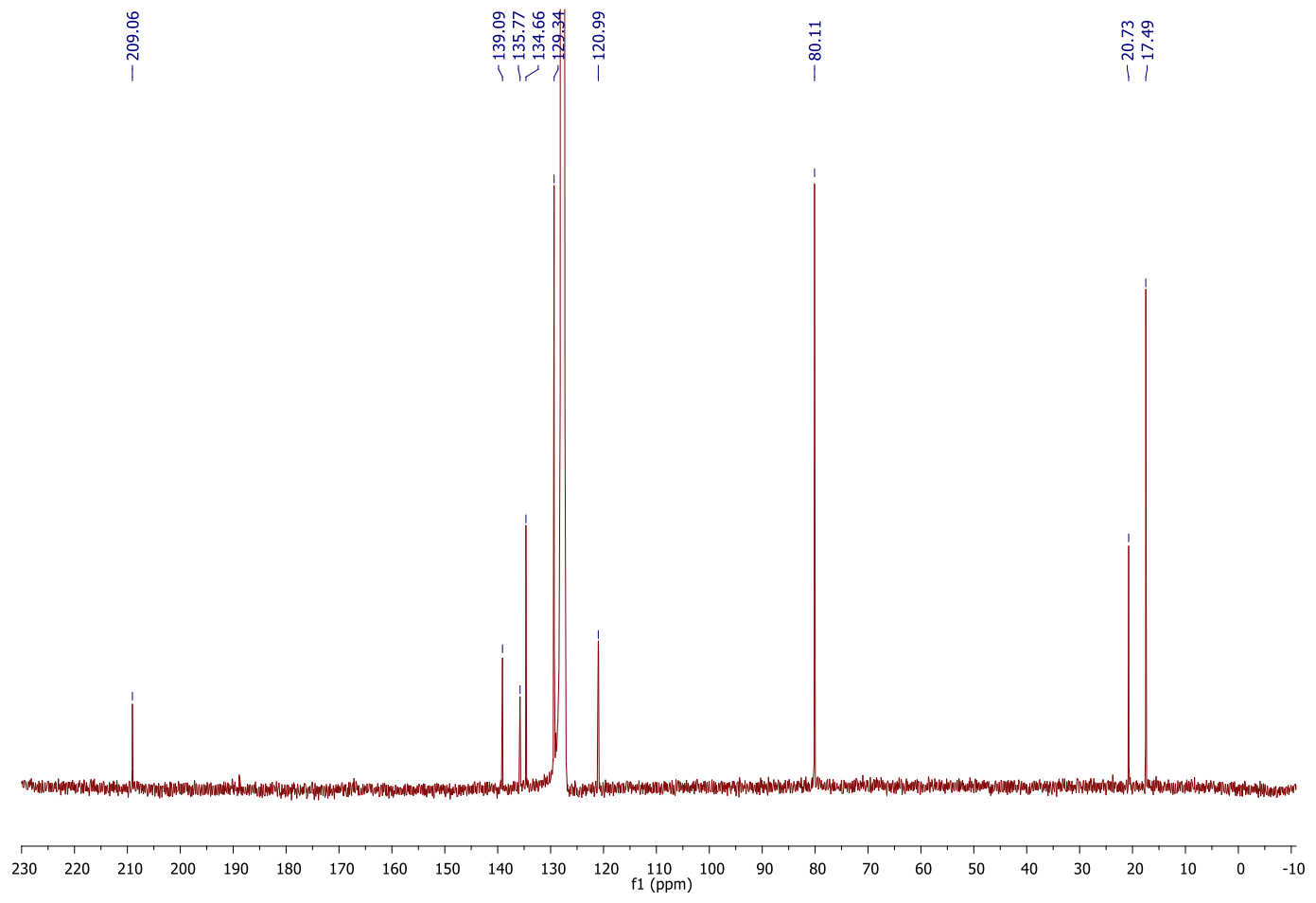

Figure S2: ${ }^{13} \mathrm{C}\left\{{ }^{1} \mathrm{H}\right\}$ NMR of (IMes) $\mathrm{AgRp}$ in $\mathrm{C}_{6} \mathrm{D}_{6}$

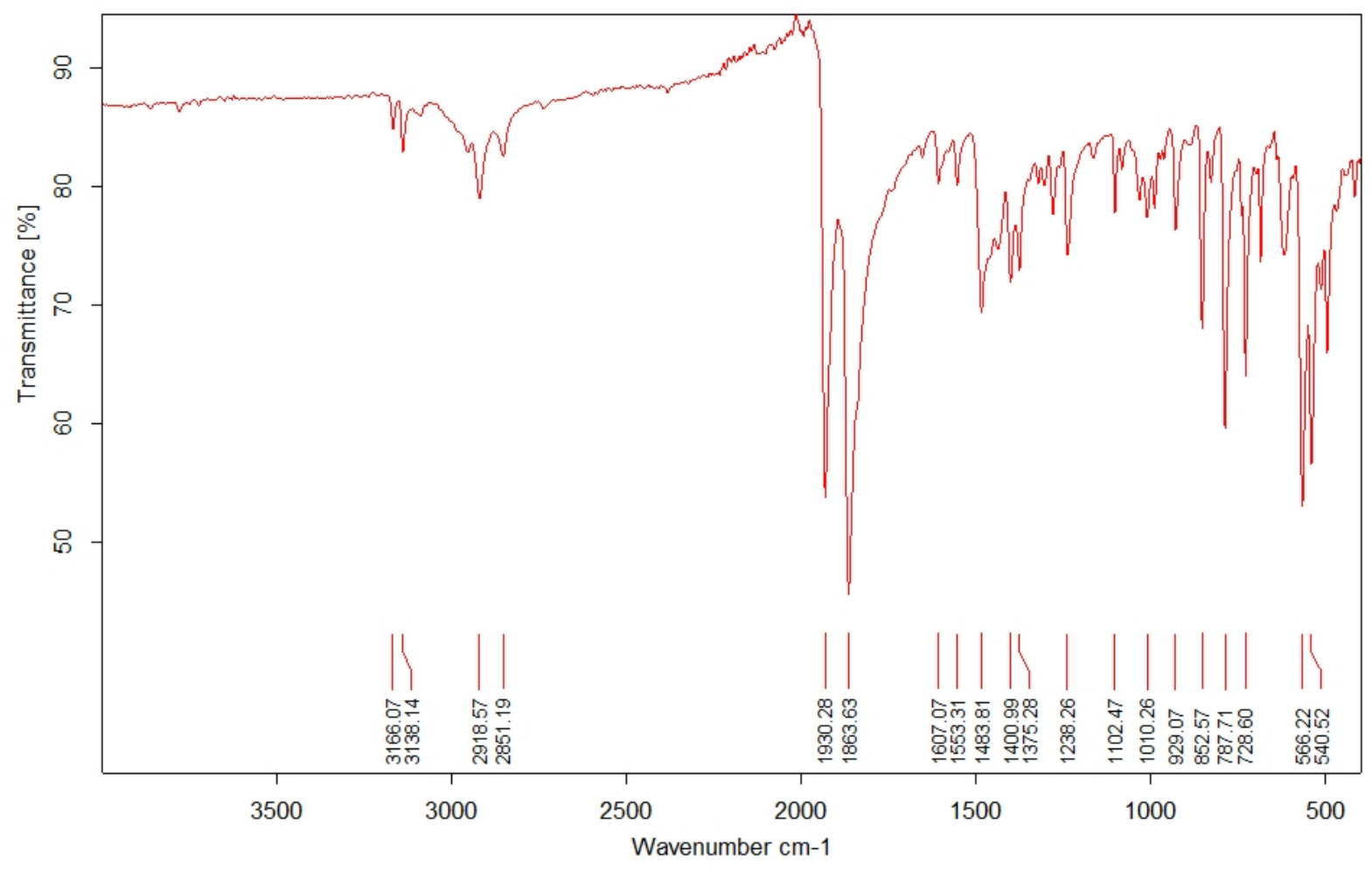

Figure S3 : FT-IR spectrum of (IMes)AgRp 


\section{(IPr)Ag-Rp.}

(IPr)AgCl (0.0849 g, $0.160 \mathrm{mmol}, 1$ equiv) was dissolved in toluene $(10 \mathrm{~mL})$, and $\mathrm{NaRp}(0.0783 \mathrm{~g}, 0.320$ mmol, 2 equiv) was added to the solution. The solution was stirred for $24 \mathrm{~h}$ at room temperature. The solution was filtered through Celite, and the filtrate was evaporated to dryness. The remaining solid was suspended in pentane $(10 \mathrm{~mL})$ and stirred vigorously for $30 \mathrm{~min}$. The suspension was filtered through a fritted glass filter, and the off-white solid was washed with pentane $(3 \times 5 \mathrm{~mL})$ and then dried in vacuo. Yield: $0.0891 \mathrm{~g}, 0.123 \mathrm{mmol}, 77 \%$. The solid was stored in a glovebox freezer at $-36{ }^{\circ} \mathrm{C}$. X-ray quality crystals were grown by vapor diffusion of pentane into a concentrated toluene solution at $-36{ }^{\circ} \mathrm{C} .{ }^{1} \mathrm{H}$ NMR (400 MHz, $\left.\mathrm{C}_{6} \mathrm{D}_{6}\right): \delta 7.21(\mathrm{t}, \mathrm{J}=7.8 \mathrm{~Hz}, 2 \mathrm{H}, \mathrm{p}-\mathrm{H}), 7.09(\mathrm{~d}, \mathrm{~J}=7.8 \mathrm{~Hz}, 4 \mathrm{H}, \mathrm{m}-\mathrm{H}), 6.32(\mathrm{~s}, 2 \mathrm{H}$, $\mathrm{NCH}), 4.77$ (s, Cp), 2.60 (sept., J = $\left.6.8 \mathrm{~Hz}, 4 \mathrm{H}, \mathrm{CH}\left(\mathrm{CH}_{3}\right)_{2}\right), 1.46\left(\mathrm{~d}, \mathrm{~J}=6.9 \mathrm{~Hz}, 12 \mathrm{H}, \mathrm{CH}\left(\mathrm{CH}_{3}\right)_{2}\right), 1.10(\mathrm{~d}$, $\left.\mathrm{J}=6.9 \mathrm{~Hz}, 12 \mathrm{H}, \mathrm{CH}\left(\mathrm{CH}_{3}\right)_{2}\right) .{ }^{13} \mathrm{C}\left\{{ }^{1} \mathrm{H}\right\} \mathrm{NMR}\left(125 \mathrm{MHz}, \mathrm{C}_{6} \mathrm{D}_{6}\right): \delta 208.6(\mathrm{CO}), 145.7,135.0,130.4,124.0$, 121.0, $80.0(\mathrm{Cp}), 28.7,24.5,23.6$. Note: Even after 10000 scans on a near-saturated solution, the ${ }^{13} \mathrm{C}$ signal for the carbene carbon was not detected. IR (solid, $\mathrm{cm}^{-1}$ ): 1936 (vCO), 1868 (vCO), 755, 565. Anal. Calcd for $\mathrm{C}_{34} \mathrm{H}_{41} \mathrm{AgN}_{2} \mathrm{O}_{2} \mathrm{Ru}$ : C, 56.82; H, 5.75; N, 3.90. Found: C, 55.88; H, 5.56; N, 3.98. Although the combustion analysis does not show $\% \mathrm{C}$ within $0.4 \%$ of the calculated value, NMR and IR data are included as indications of purity.

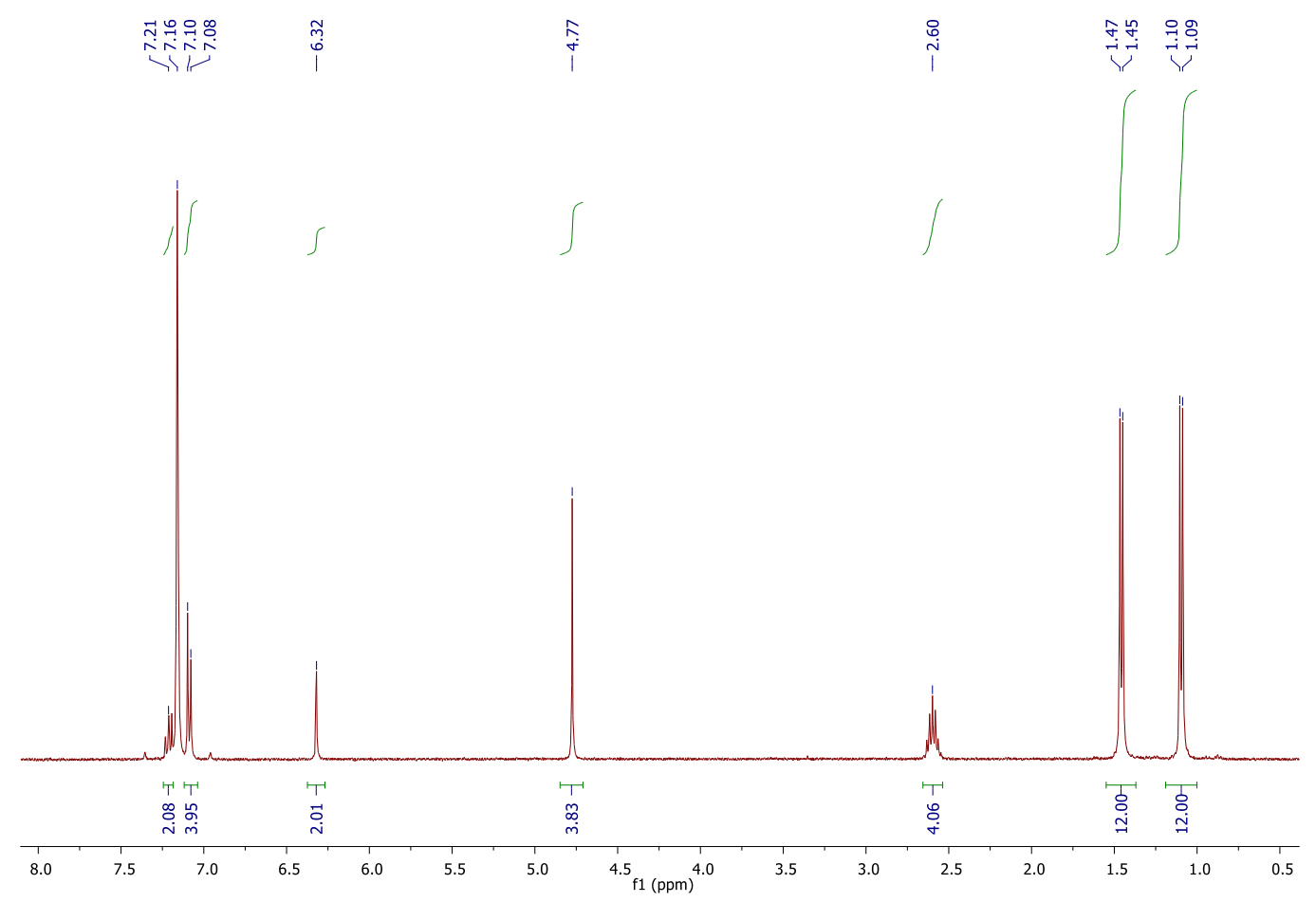

Figure $\mathrm{S} 4:{ }^{1} \mathrm{H}$ NMR spectrum of (IPr)AgRp in $\mathrm{C}_{6} \mathrm{D}_{6}$ 


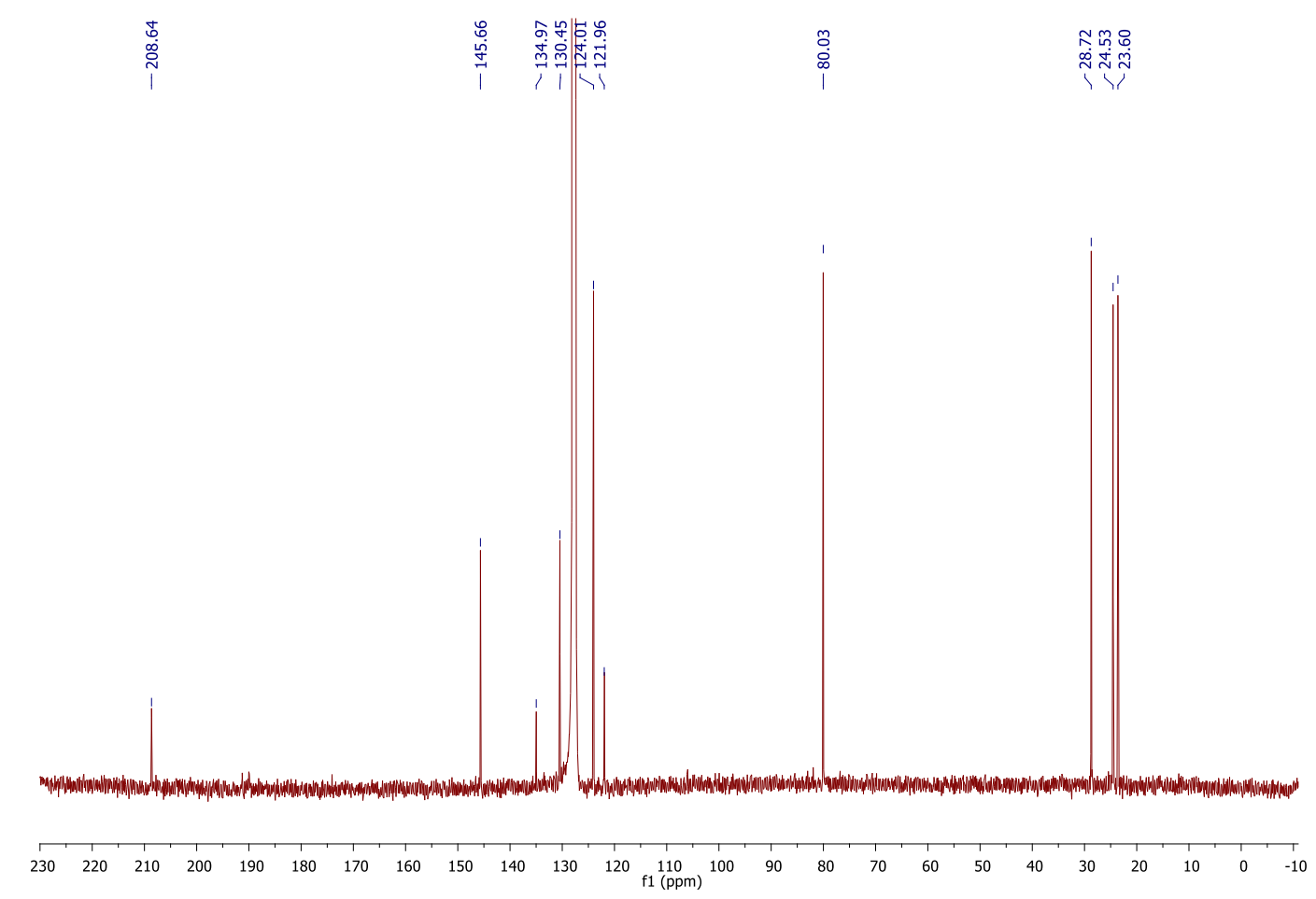

Figure S5: ${ }^{13} \mathrm{C}\left\{{ }^{1} \mathrm{H}\right\}$ NMR spectrum of (IPr)AgRp in $\mathrm{C}_{6} \mathrm{D}_{6}$

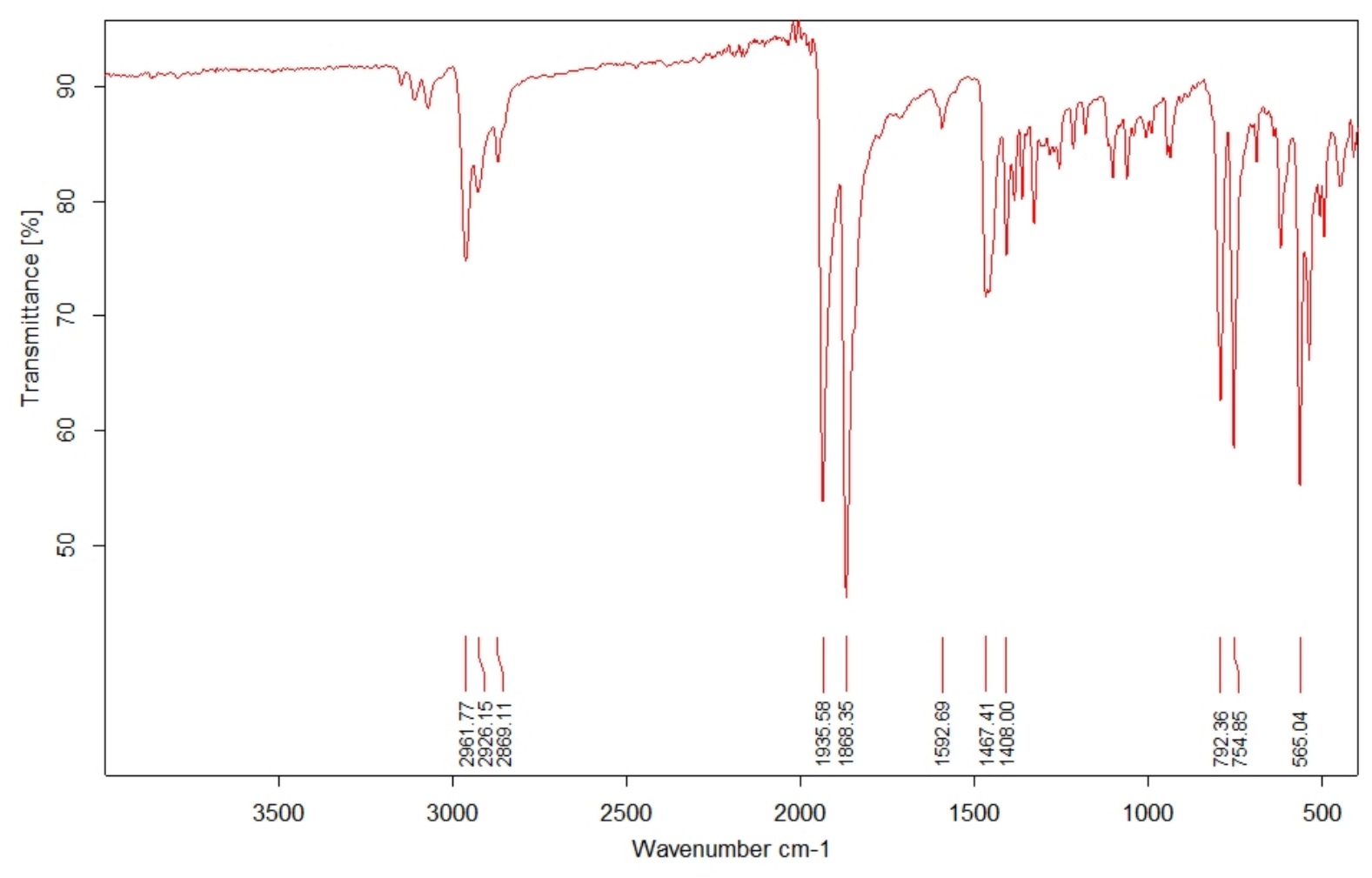

Figure S6 : FT-IR spectrum of (IPr)AgRp 


\section{(IMes)Ag-Fp.}

(IMes) $\mathrm{AgCl}(0.0674 \mathrm{~g}, 0.150 \mathrm{mmol}, 1$ equiv) was dissolved in toluene $(10 \mathrm{~mL})$, and $\mathrm{KFp}(0.0650 \mathrm{~g}, 0.300$ mmol, 2 equiv) was added to the solution. The solution was stirred for $24 \mathrm{~h}$ at room temperature. The solution was filtered through Celite, and the filtrate was evaporated to dryness. The remaining solid was suspended in pentane $(10 \mathrm{~mL})$ and stirred vigorously for $30 \mathrm{~min}$. The suspension was filtered through a fritted glass filter, and the yellow solid was washed with pentane $(3 \times 5 \mathrm{~mL})$ and then dried in vacuo. Yield: $0.0571 \mathrm{~g}, 0.096 \mathrm{mmol}, 64 \%$. The solid was stored in a glovebox freezer at $-36{ }^{\circ} \mathrm{C} .{ }^{1} \mathrm{H}$ NMR $(500$ $\left.\mathrm{MHz}, \mathrm{C}_{6} \mathrm{D}_{6}\right): \delta 7.16(\mathrm{~s}, 4 \mathrm{H}, \mathrm{m}-\mathrm{H}), 6.75$ (s, 2H, NCH), 4.33 (s, Cp), 2.07 (s, 6H, p- $\left.\mathrm{CH}_{3}\right), 2.03$ (s, 12H, o$\left.\mathrm{CH}_{3}\right) .{ }^{13} \mathrm{C}\left\{{ }^{1} \mathrm{H}\right\}$ NMR $\left(125 \mathrm{MHz}, \mathrm{C}_{6} \mathrm{D}_{6}\right): \delta 222.4(\mathrm{CO}), 139.4,136.1,135.0,129.6,121.2,76.8(\mathrm{Cp}), 21.0$, 17.8. Note: Even after 10000 scans on a near-saturated solution, the ${ }^{13} \mathrm{C}$ signal for the carbene carbon was not detected. IR (solid, $\mathrm{cm}^{-1}$ ): 1905 ( $\left.\mathrm{vCO}\right), 1844(\mathrm{vCO}), 655,584$. Anal. Calcd for $\mathrm{C}_{28} \mathrm{H}_{29} \mathrm{~N}_{2} \mathrm{O}_{2} \mathrm{AgFe}$ : C, 57.07; H, 4.96; N, 4.75. Found: C, 57.27; H, 4.68; N, 4.51.

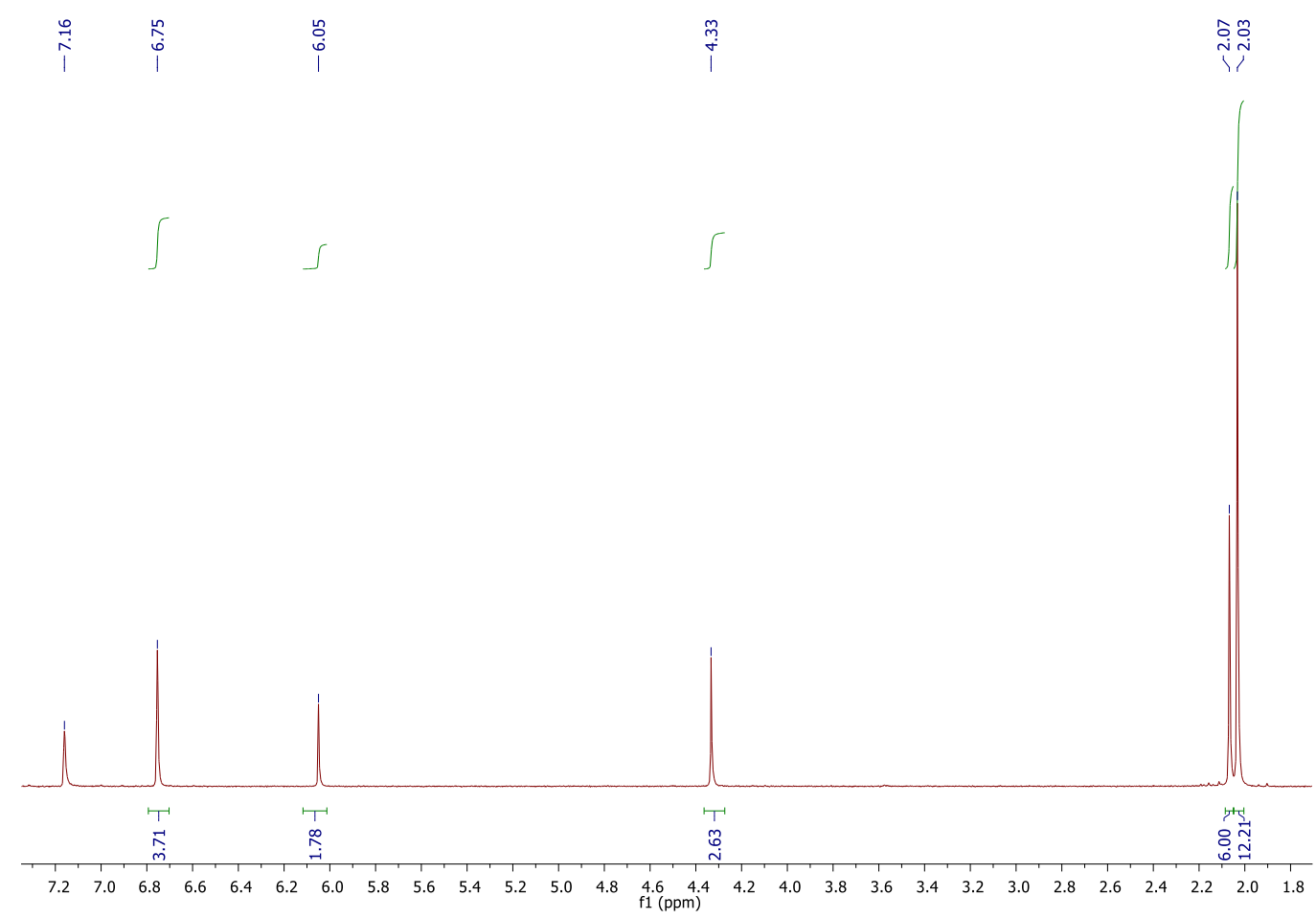

Figure $\mathrm{S} 7: \mathrm{H}^{1} \mathrm{NMR}$ spectrum of (IMes)AgFp in $\mathrm{C}_{6} \mathrm{D}_{6}$ 


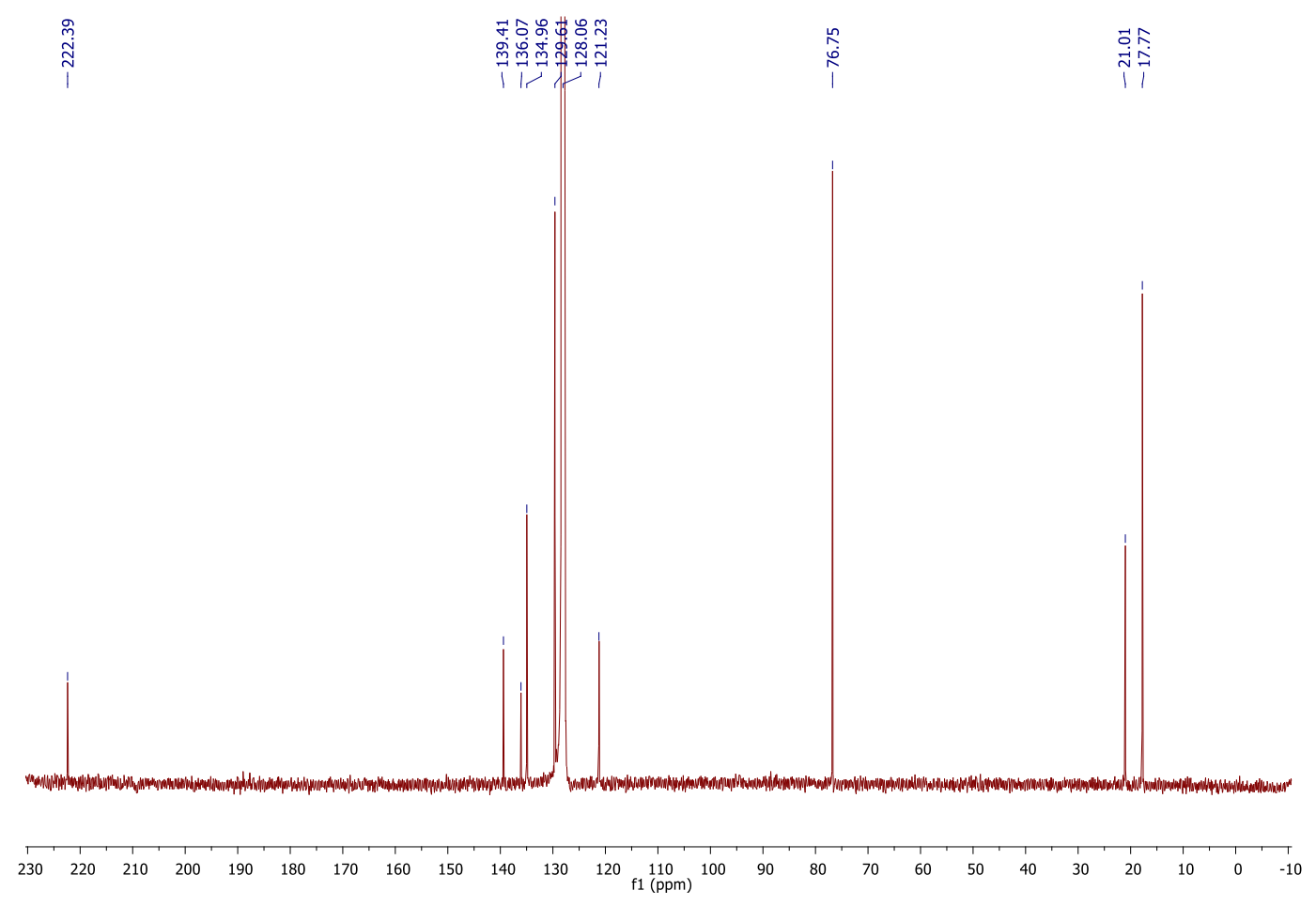

Figure S8 : ${ }^{13} \mathrm{C}\left\{{ }^{1} \mathrm{H}\right\}$ NMR spectrum of (IMes)AgFp in $\mathrm{C}_{6} \mathrm{D}_{6}$

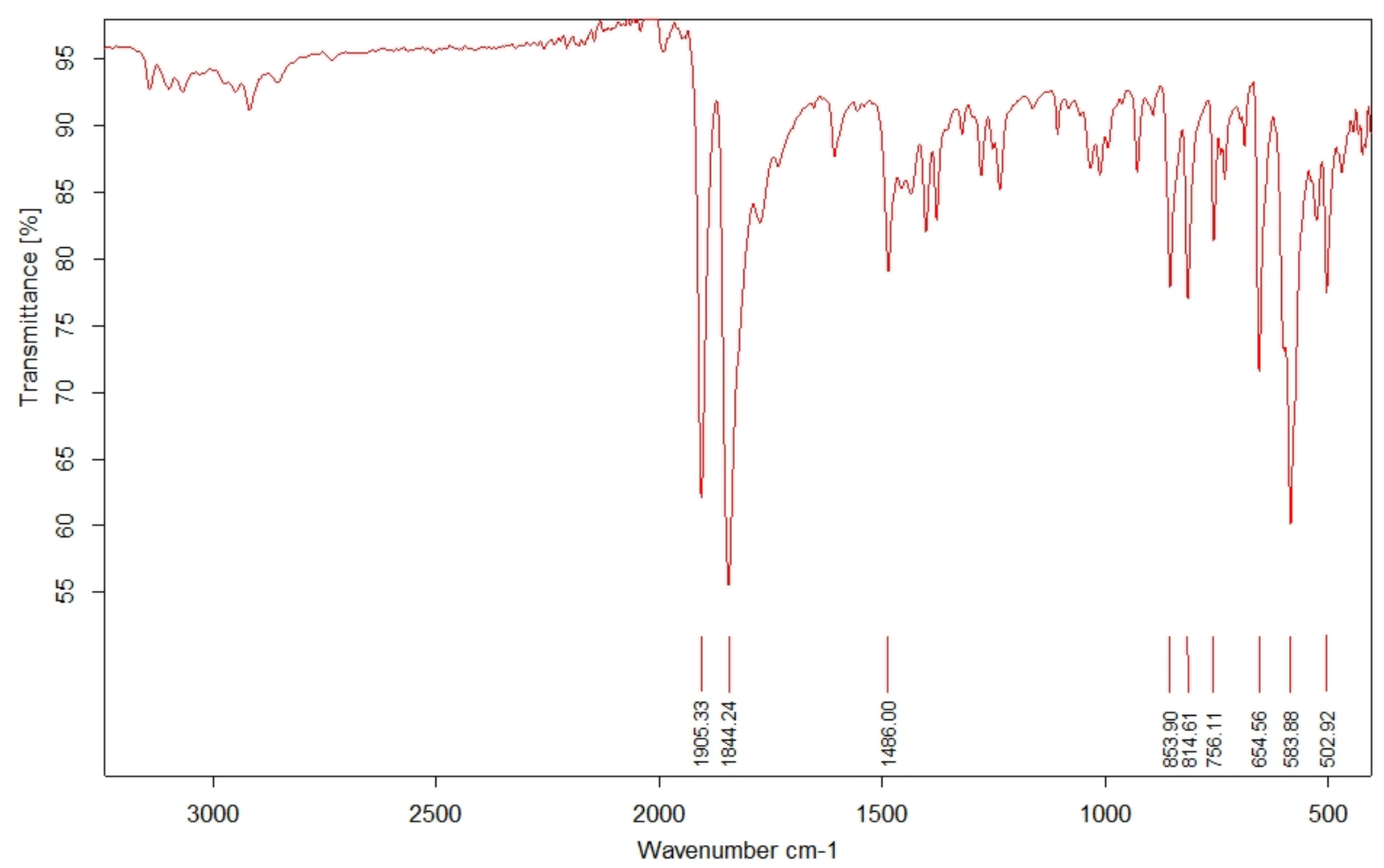

Figure S9: FT-IR spectrum of (IMes)AgFp 


\section{General procedure for catalyst optimization.}

In a nitrogen filled glovebox, the catalyst (5.0 mg, 0.2 equiv), diphenylacetylene ( 1 equiv) and an internal standard (hexamethylbenzene or 1,3,5-trimethoxybenzene, 1 equiv) were dissolved in xylenes $(1 \mathrm{~mL})$, transferred to a J-Young NMR tube, and sealed. (The transfer was done in two steps: First, the maximum amount of the solids were dissolved in $0.7 \mathrm{~mL}$ of xylenes and transferred. The vial was washed with another $0.3 \mathrm{~mL}$ of xylenes and the washings were then transferred.) The J-Young tube was inverted multiple times to make sure that all the solids dissolved and then connected to a Schlenk line containing $\mathrm{H}_{2}$ gas $(1 \mathrm{~atm})$. After degassing the solution using three 5-minute freeze-pump-thaw cycles, the sample was frozen again, exposed to $\mathrm{H}_{2}$ and allowed to thaw and equilibrate for 30 minutes. The J-Young tube was then resealed and heated in an oil bath at $150{ }^{\circ} \mathrm{C}$ for $24 \mathrm{~h}$. The J-Young tube was then transferred back into the glovebox, and the solution was transferred into a scintillation vial and dried in vacuo. The dried product was then dissolved in toluene- $\mathrm{d}_{8}$ and pipette-filtered through Celite into a J-Young tube. The ${ }^{1} \mathrm{H}-$ NMR spectrum was recorded. (The catalyst impurities present can be removed by pipette-filtering the product mixture through silica: See figure S11)

The following signals, determined by measuring spectra of authentic samples (diphenylacetylene \& stilbene isomers) or comparison to literature data in $\mathrm{C}_{6} \mathrm{D}_{6}{ }^{17}$ (1,2-diphenylethane), were used to quantify the starting materials and the products. ${ }^{1} \mathrm{H}$ NMR $\left(500 \mathrm{MHz}\right.$, toluene- $\left.\mathrm{d}_{8}\right)$ : Diphenylacetylene: $7.46(\mathrm{~d}, 4 \mathrm{H})$; trans-stilbene: 7.29 (d, 4H); cis-stilbene: 6.44 (s, 2H); 1,2-Diphenylethane: $2.72(\mathrm{~s}, 4 \mathrm{H})$. 


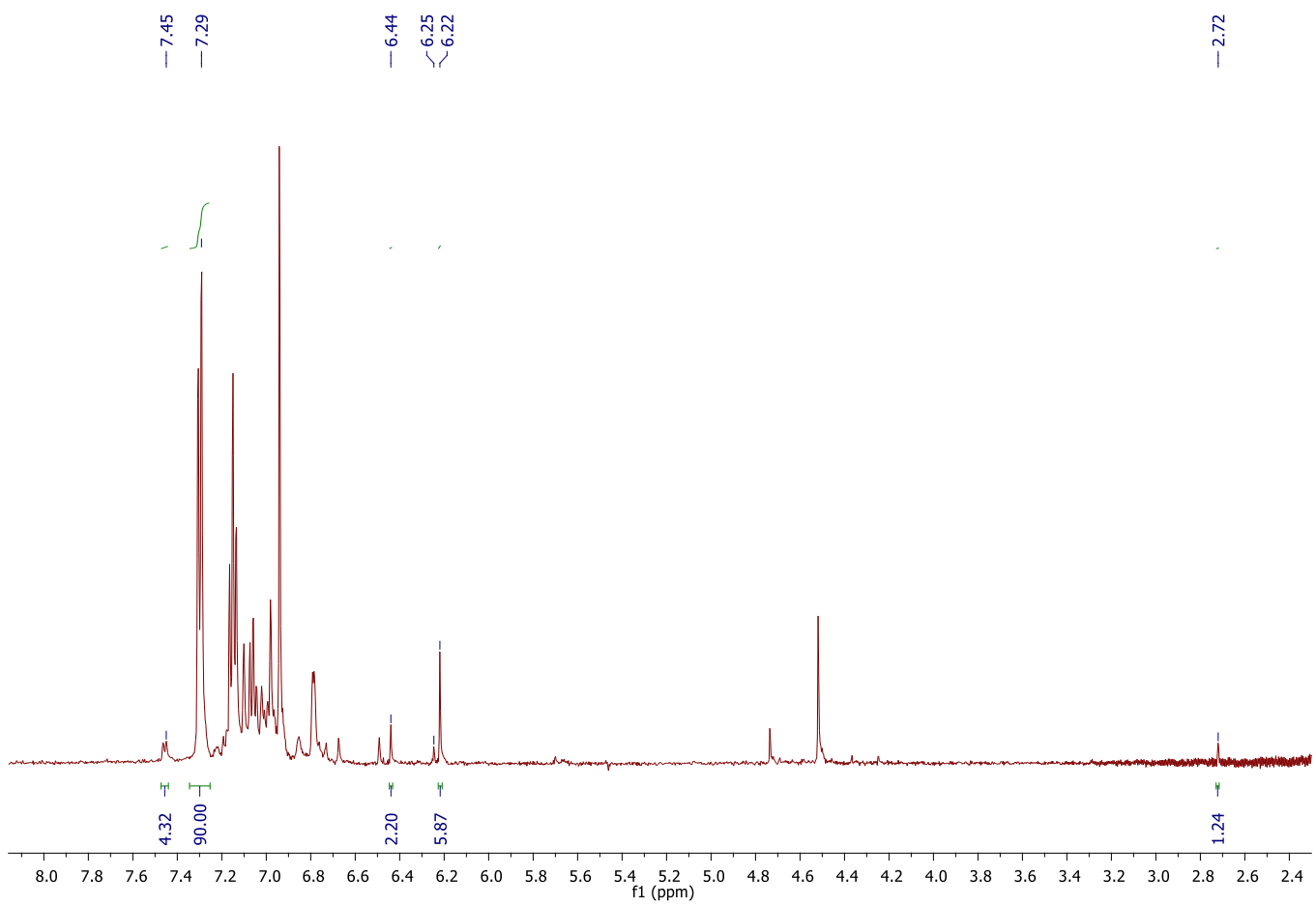

Figure S10: Representative spectrum for the catalyst optimization: $\mathrm{H}^{1} \mathrm{NMR}$ spectrum of the catalytic semi-hydrogenation of diphenylacetylene by the optimum catalyst (IMes)AgRp (Only the peak values and the integrations used to quantify the products have been marked for clarity) 
a)

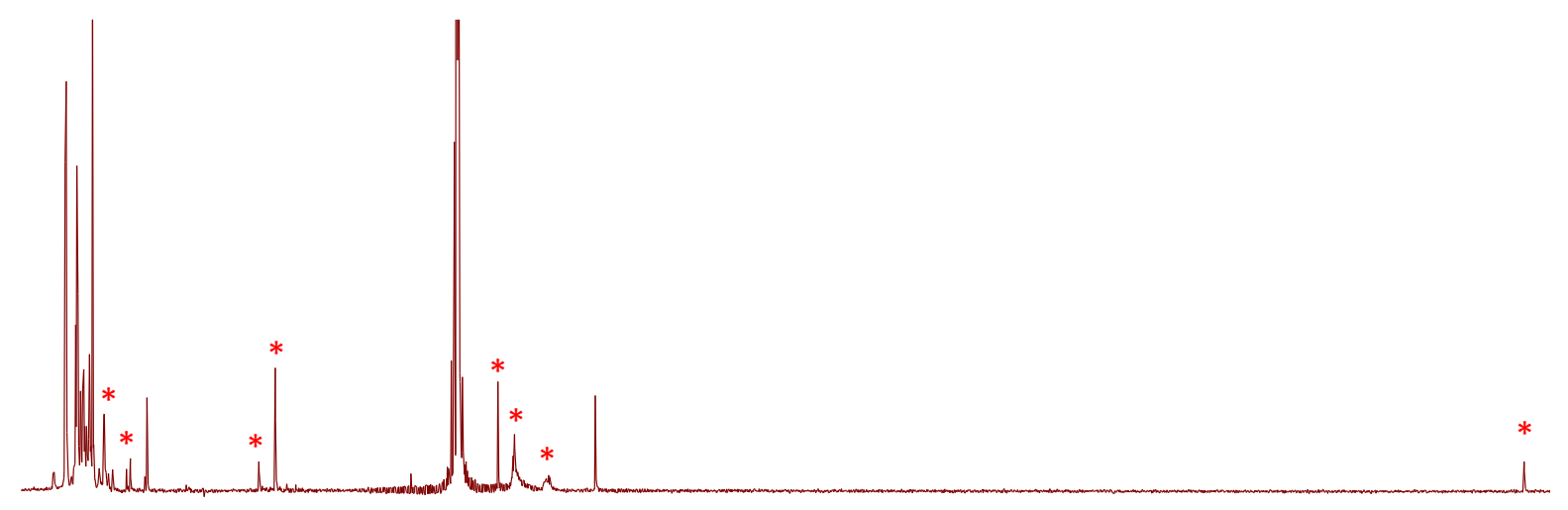

b)

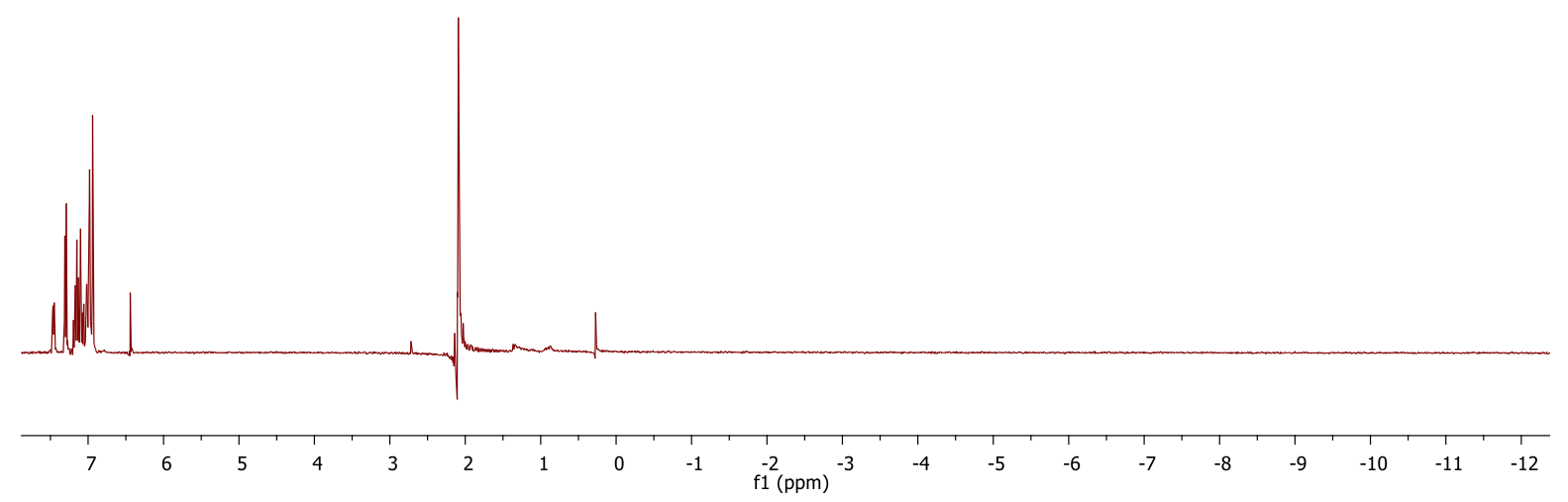

Figure S11: $\mathrm{H}^{1} \mathrm{NMR}$ spectrum of the catalytic semi-hydrogenation of diphenylacetylene by (IMes)AgRp a) before $\mathrm{b}$ ) after pipette-filtering through silica (The peaks for the $\mathrm{RpH}(4.52,-12.04)$ and for additional Cp (4.74) and IMes species (6.69-6.85, 070-1.57) containing Ru and Ag have been marked with *.) 


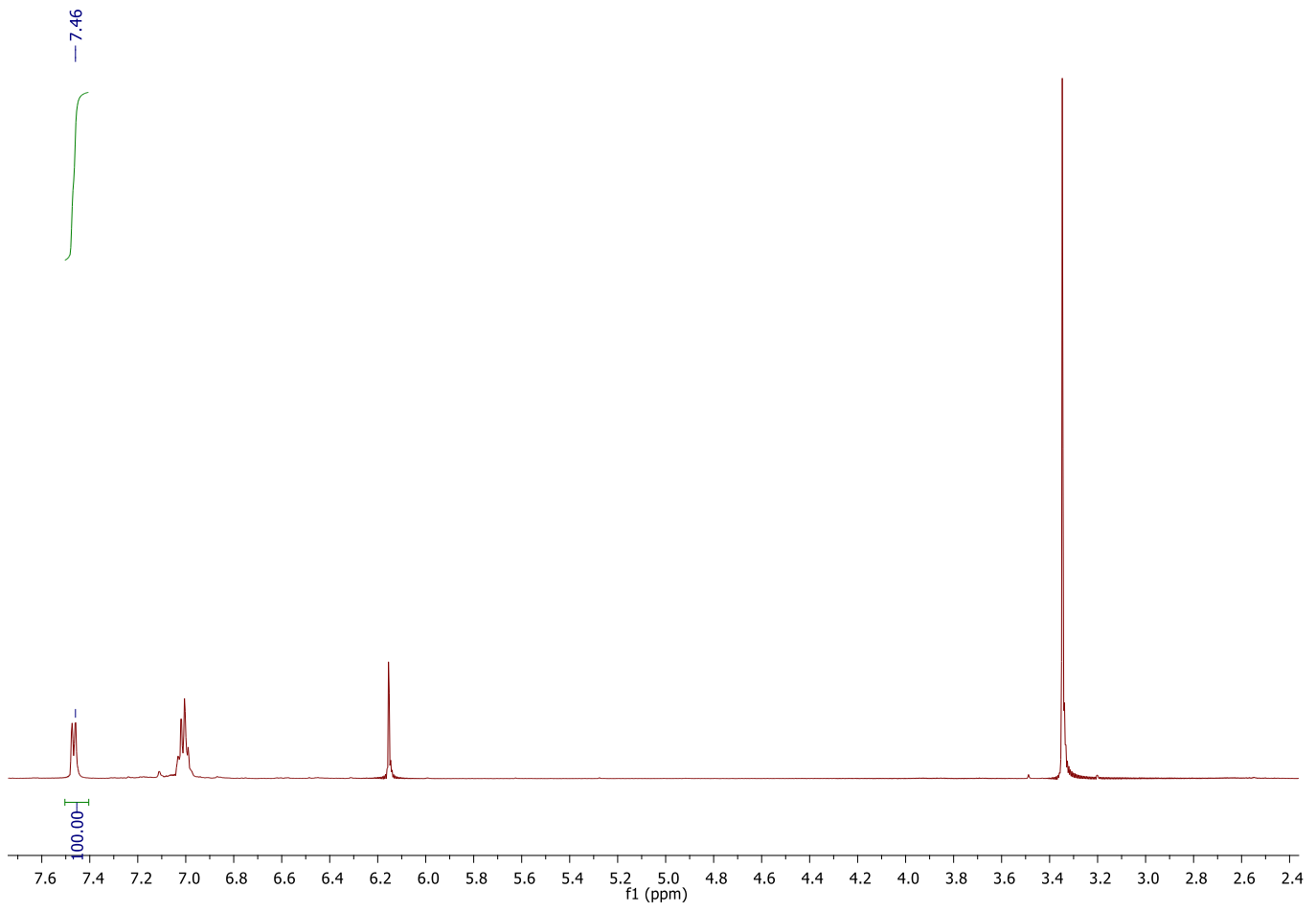

Figure S12: ${ }^{1} \mathrm{H}$ NMR spectrum of the catalytic semi-hydrogenation of diphenylacetylene by (IPr)AgOAc (Only the peak values and the integrations used to quantify the products have been marked for clarity) 


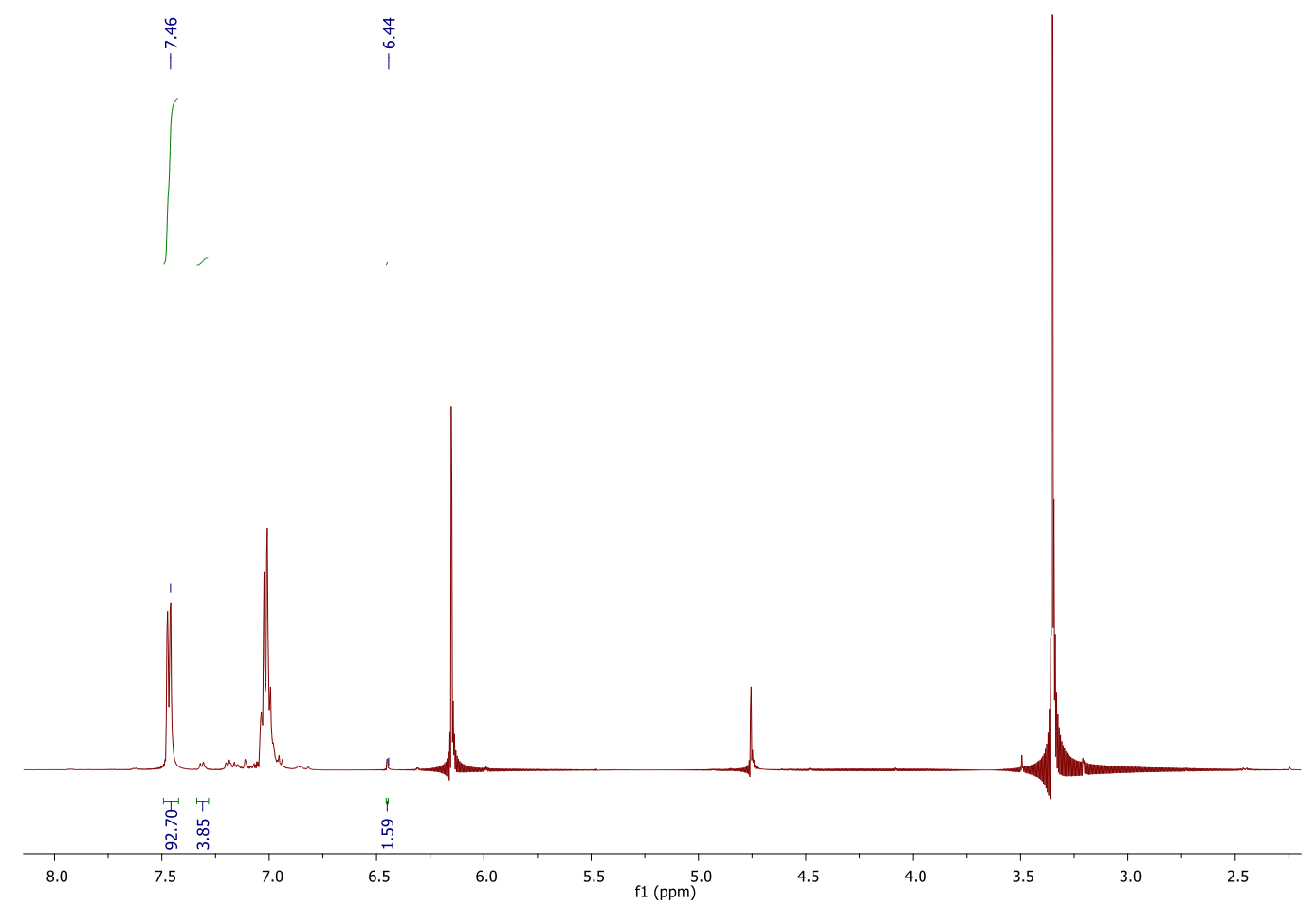

Figure S13: ${ }^{1} \mathrm{H}$ NMR spectrum of the catalytic semi-hydrogenation of diphenylacetylene by $\mathrm{Rp}_{2}$ (Only the peak values and the integrations used to quantify the products have been marked for clarity) 


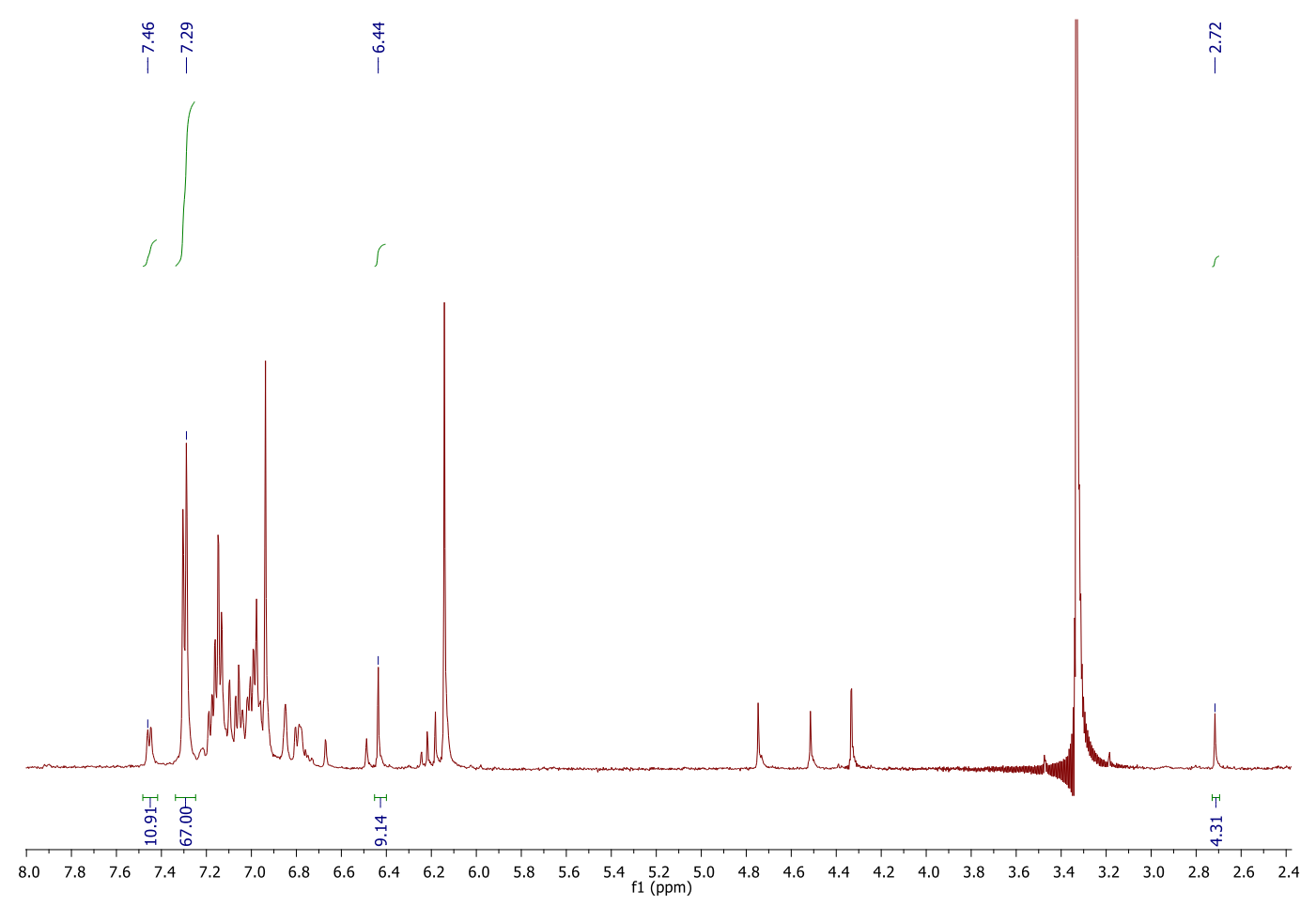

Figure S14: ${ }^{1} \mathrm{H}$ NMR spectrum of the catalytic semi-hydrogenation of diphenylacetylene by (IMes)AgRp with a drop of $\mathrm{Hg}$ (Only the peak values and the integrations used to quantify the products have been marked for clarity)

\section{General procedure for catalytic semi-hydrogenation of alkynes by (IMes)AgRp.}

In a nitrogen filled glovebox, (IMes)Ag-Rp (5.0 mg, 0.2 equiv), the alkyne ( 1 equiv) and an internal standard (hexamethylbenzene or 1,3,5-trimethoxybenzene, 1 equiv) were dissolved in xylenes ( $1 \mathrm{~mL})$, transferred to a J-Young NMR tube, and sealed. (The transfer was done in two steps: First, the maximum amount of the solids were dissolved in $0.7 \mathrm{~mL}$ of xylenes and transferred. The vial was washed with another $0.3 \mathrm{~mL}$ of xylenes and the washings were then transferred.) The J-Young tube was inverted multiple times to make sure that all the solids dissolved and then connected to a Schlenk line containing $\mathrm{H}_{2}$ gas $(1 \mathrm{~atm})$. After degassing the solution using three 5-minute freeze-pump-thaw cycles, the sample was frozen again, exposed to $\mathrm{H}_{2}$ and allowed to thaw and equilibrate for 30 minutes. The J-Young tube was then resealed and heated in an oil bath at $150{ }^{\circ} \mathrm{C}$ for $24 \mathrm{~h}$. The J-Young tube was then transferred back into the glovebox, and the solution was transferred into a scintillation vial and dried in vacuo. The dried product was then dissolved in toluene- $\mathrm{d}_{8}$ or $\mathrm{CDCl}_{3}$ depending on the alkyne and pipette-filtered through Celite into a J-Young tube. The ${ }^{1} \mathrm{H}-\mathrm{NMR}$ spectrum was recorded. 


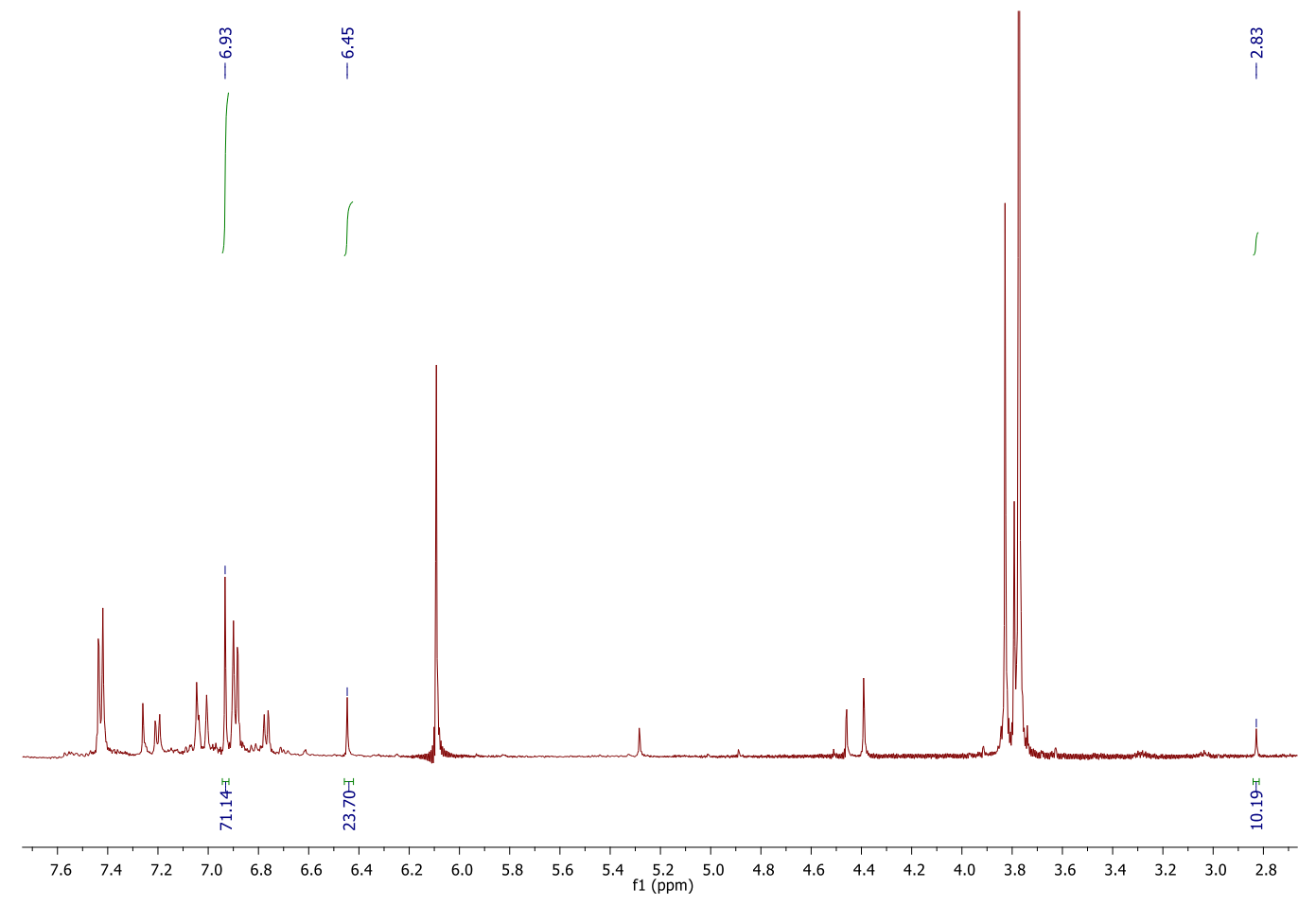

Figure S15: ${ }^{1} \mathrm{H}$ NMR spectrum of the catalytic semi-hydrogenation of 1,2-bis(4-methoxyphenyl)ethyne (Only the peak values and the integrations used to quantify the products have been marked for clarity)

The following signals, mentioned in the literature were used to quantify the starting materials and the products. ${ }^{1} \mathrm{H}$ NMR $\left(500 \mathrm{MHz}, \mathrm{CDCl}_{3}\right)$ : 1,2-Bis(4-methoxyphenyl)ethyne ${ }^{18}: 6.87$ (d, 4H); (E)-1,2-bis(4methoxyphenyl)ethene ${ }^{19}: 6.93(\mathrm{~s}, 2 \mathrm{H})$; $(Z)$-1,2-bis(4-methoxyphenyl)ethene ${ }^{20}: 6.44$ (s, 2H); 1,2-bis(4methoxyphenyl)ethane ${ }^{21}: 2.84(\mathrm{~s}, 4 \mathrm{H})$. 


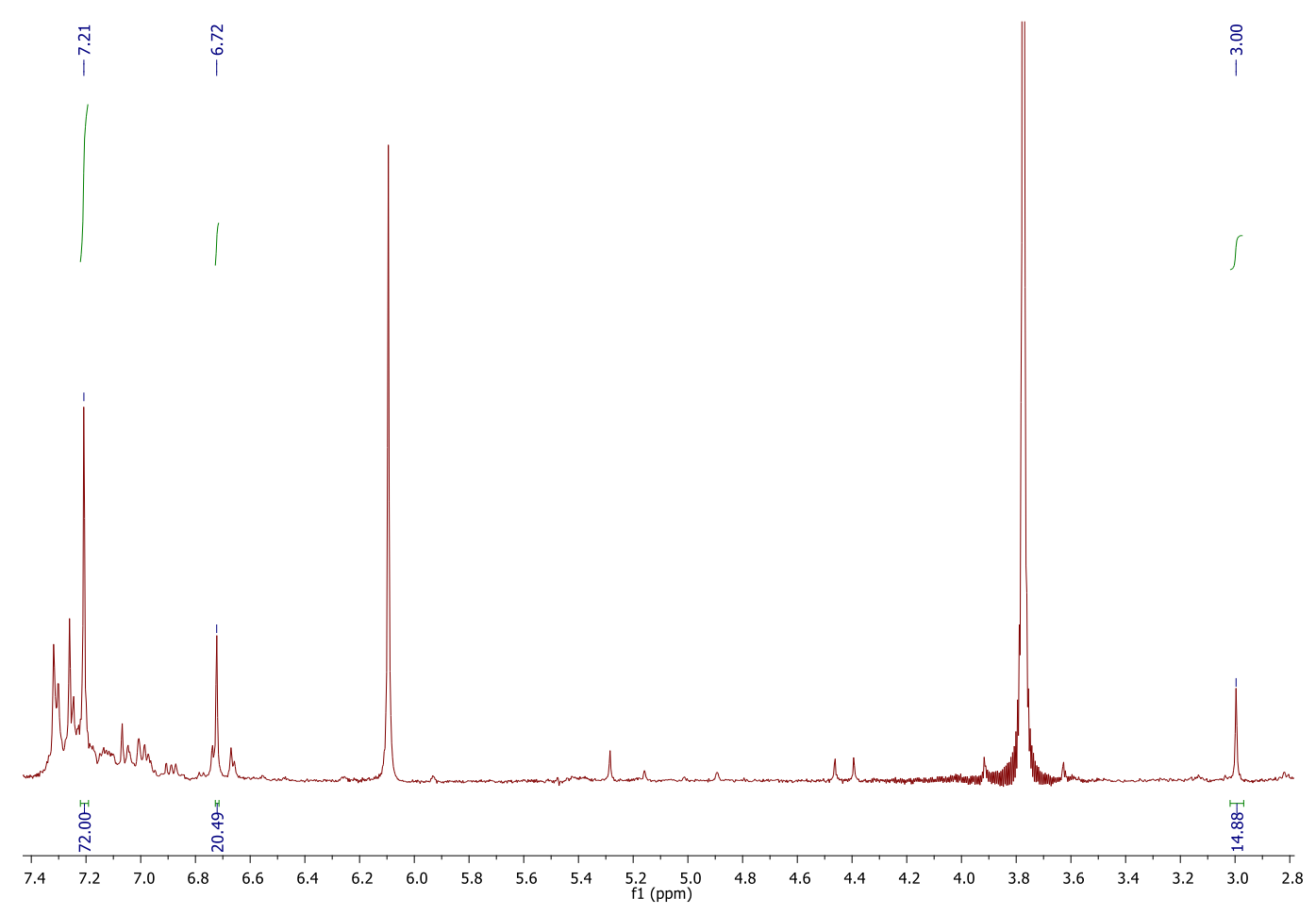

Figure S16: ${ }^{1} \mathrm{H}$ NMR spectrum of the catalytic semi-hydrogenation of 1,2-bis(4(trifluoromethyl)phenyl)ethyne (Only the peak values and the integrations used to quantify the products have been marked for clarity)

The following signals, mentioned in the literature data were used to quantify the starting materials and the products. ${ }^{1} \mathrm{H}$ NMR (500 MHz, $\mathrm{CDCl}_{3}$ ): 1,2-bis(4-(trifluoromethyl)phenyl)ethyne ${ }^{22}: 6.87$ (d, 4H); (E)-1,2bis(4-(trifluoromethyl)phenyl)ethene ${ }^{23}: 7.21(\mathrm{~s}, 2 \mathrm{H}) ;(Z)$-1,2-bis(4-(trifluoromethyl)phenyl)ethene ${ }^{24}: 6.72$ (s, 2H); 1,2-bis(4-(trifluoromethyl)phenyl)ethane ${ }^{25}: 3.00$ (s, 4H). 


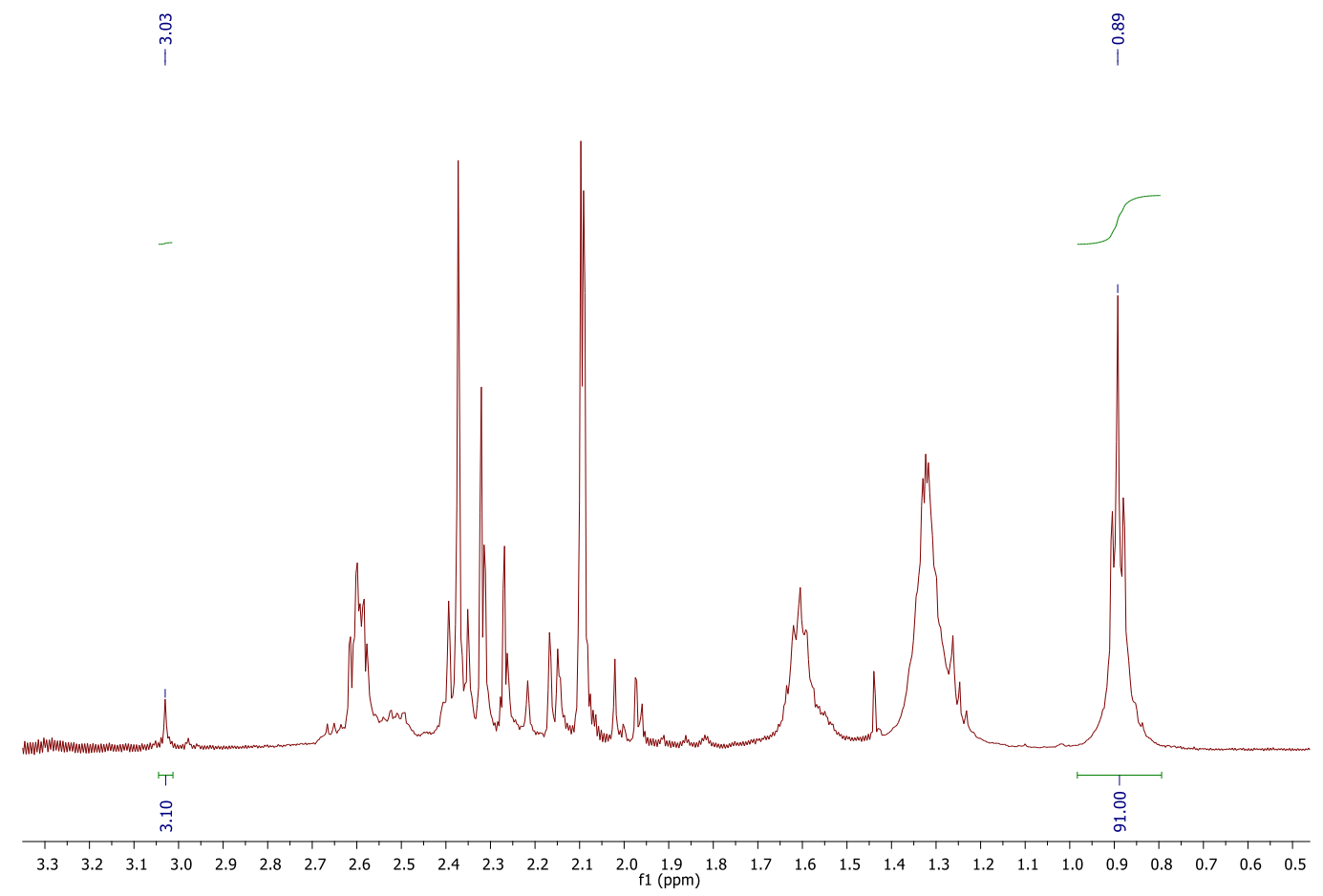

Figure S17: ${ }^{1} \mathrm{H}$ NMR spectrum of the catalytic semi-hydrogenation of 1-ethynyl-4-pentylbenzene

The following signals, mentioned in the literature data were used to quantify the starting materials and the products. ${ }^{1} \mathrm{H}$ NMR $\left(500 \mathrm{MHz}, \mathrm{CDCl}_{3}\right)$ : 1-ethynyl-4-pentylbenzene ${ }^{26}$ : 3.03 (s, 1H); 1-pentyl-4vinylbenzene ${ }^{27}: 0.89(\mathrm{t}, 3 \mathrm{H})$. 


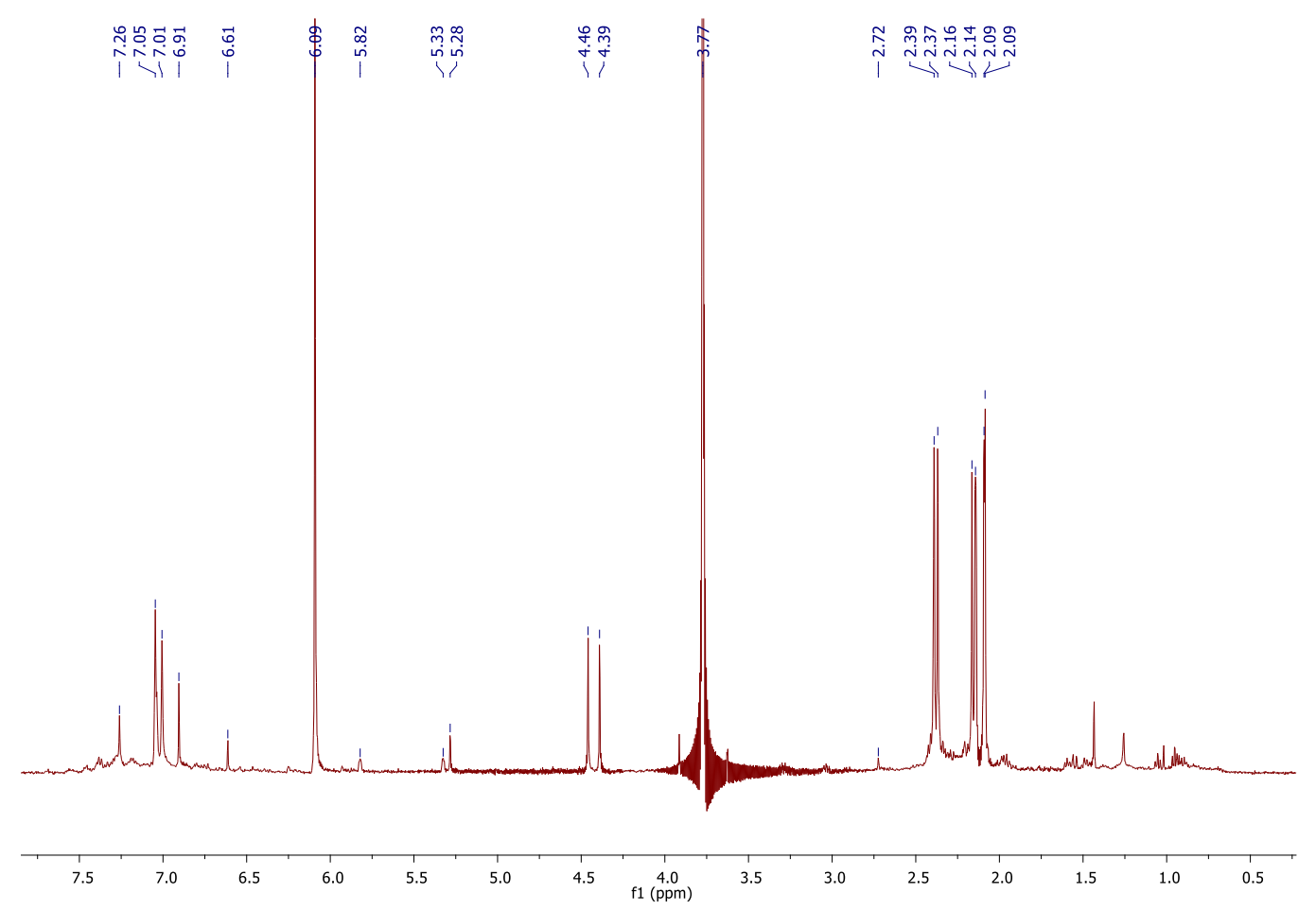

Figure S18: ${ }^{1} \mathrm{H}$ NMR spectrum of the catalytic semi-hydrogenation of 1-phenyl-1-hexyne taken in $\mathrm{CDCl}_{3}$.

\section{General procedure for the alkene isomerization}

In a nitrogen filled glovebox, (IMes)Ag-Rp (5.0 mg, 0.2 equiv) (unless indicated otherwise), the cis or trans-stilbene (1 equiv), and an internal standard (hexamethylbenzene or 1,3,5-trimethoxybenzene, 1 equiv) were dissolved in xylenes $(1 \mathrm{~mL}$ ), transferred to a J-Young NMR tube, and sealed. (The transfer was done in two steps: First, the maximum amount of the solids were dissolved in $0.7 \mathrm{~mL}$ of xylenes and transferred. The vial was washed with another $0.3 \mathrm{~mL}$ of xylenes and the washings were then transferred.) The J-Young tube was inverted multiple times to make sure that all the solids dissolved and then connected to a Schlenk line containing $\mathrm{H}_{2}$ gas ( $\left.1 \mathrm{~atm}\right)$. After degassing the solution using three 5-minute freeze-pump-thaw cycles, the sample was frozen again, exposed to $\mathrm{H}_{2}$ and allowed to thaw and equilibrate for 30 minutes. The J-Young tube was then resealed and heated in an oil bath at $150{ }^{\circ} \mathrm{C}$ for 24 $\mathrm{h}$. The J-Young tube was then transferred back into the glovebox, and the solution was transferred into a scintillation vial and dried in vacuo. The dried product was then dissolved in toluene- $\mathrm{d}_{8}$ and pipettefiltered through Celite into a J-Young tube. The ${ }^{1} \mathrm{H}-\mathrm{NMR}$ spectrum was recorded. 


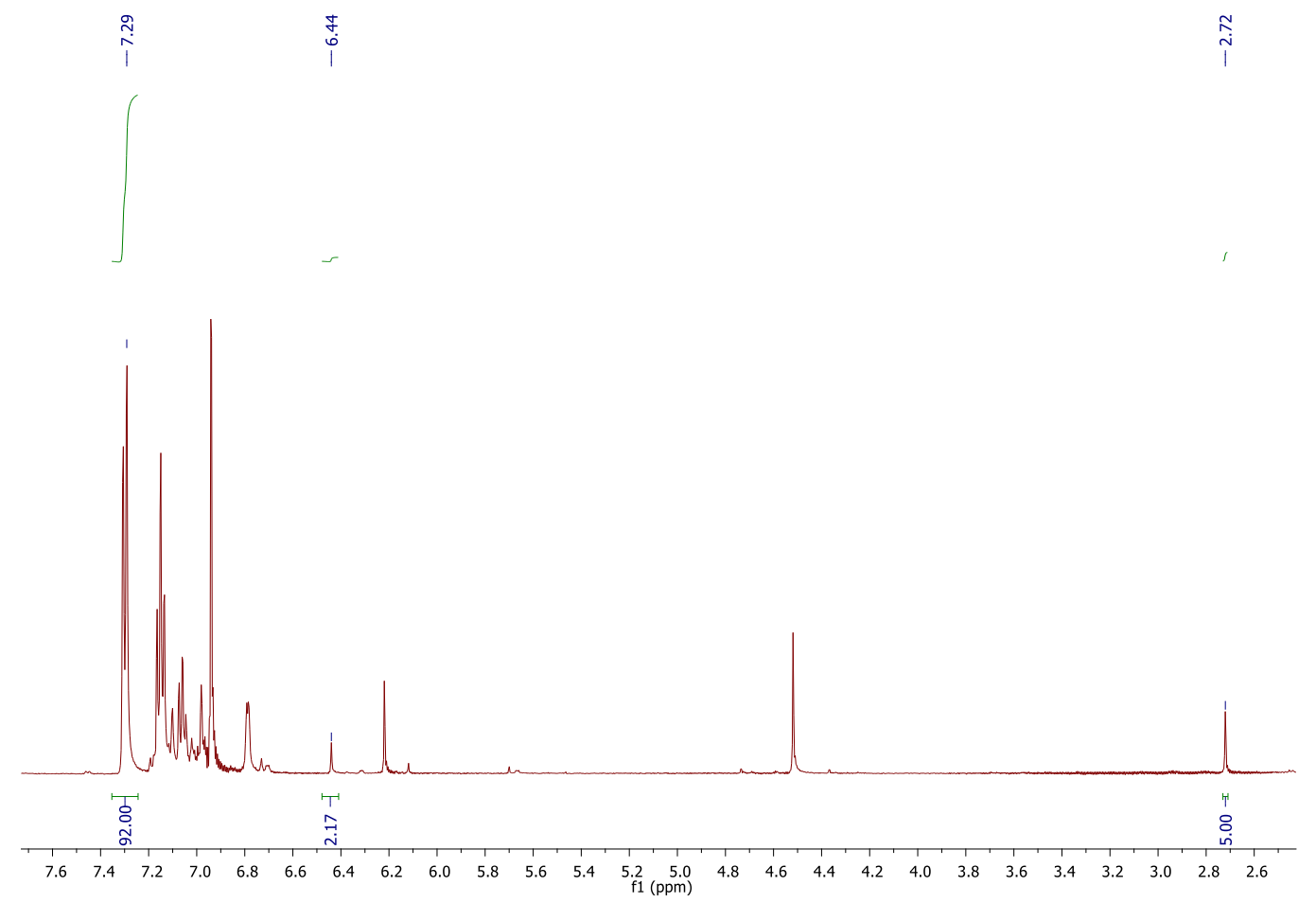

Figure S19: ${ }^{1} \mathrm{H}$ NMR spectrum of $c i s$-stilbene after the reaction under catalytic conditions. (Only the peak values and the integrations used to quantify the products have been marked for clarity) 


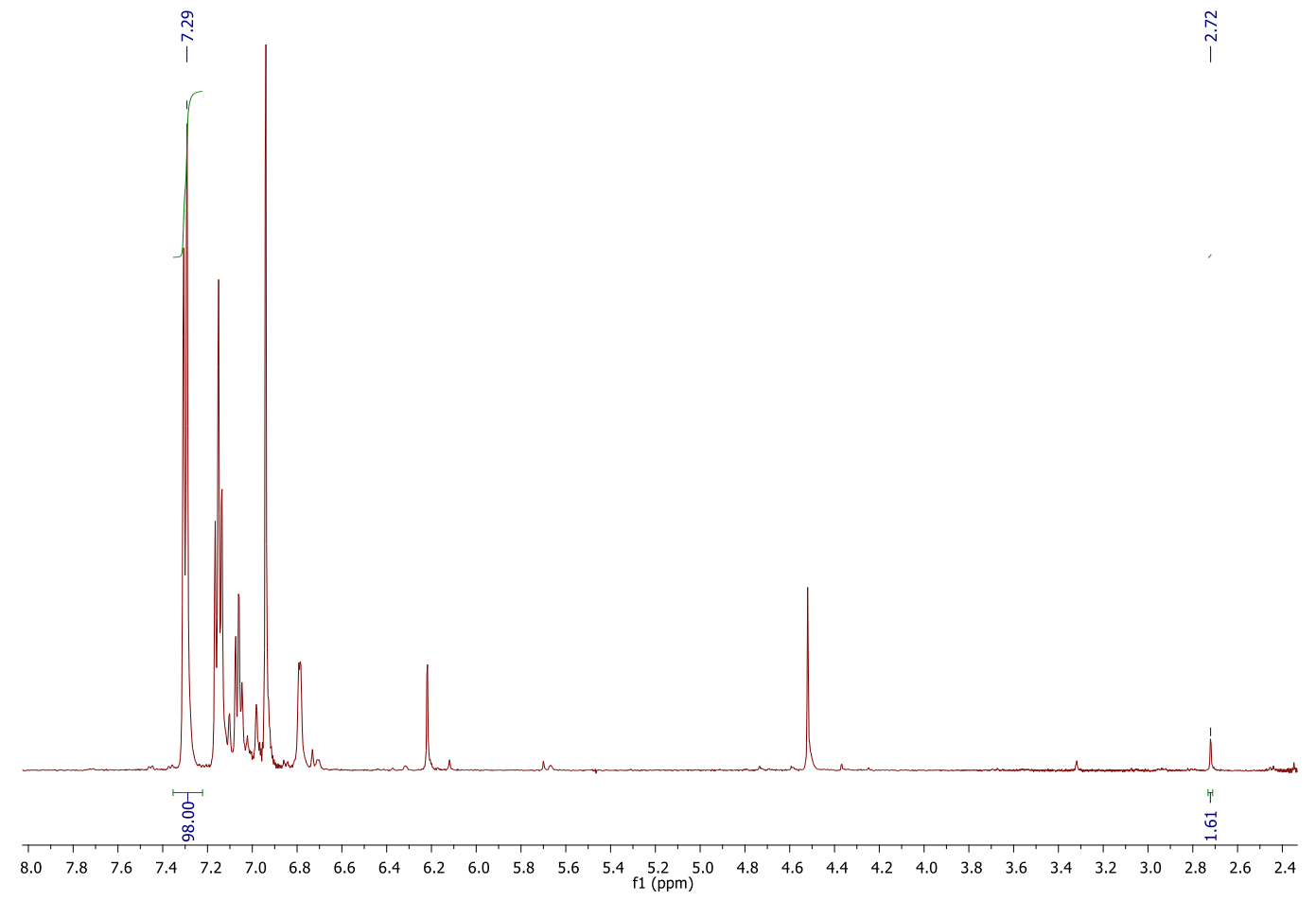

Figure S20: ${ }^{1} \mathrm{H}$ NMR spectrum of trans-stilbene after the reaction under catalytic conditions. (Only the peak values and the integrations used to quantify the products have been marked for clarity) 


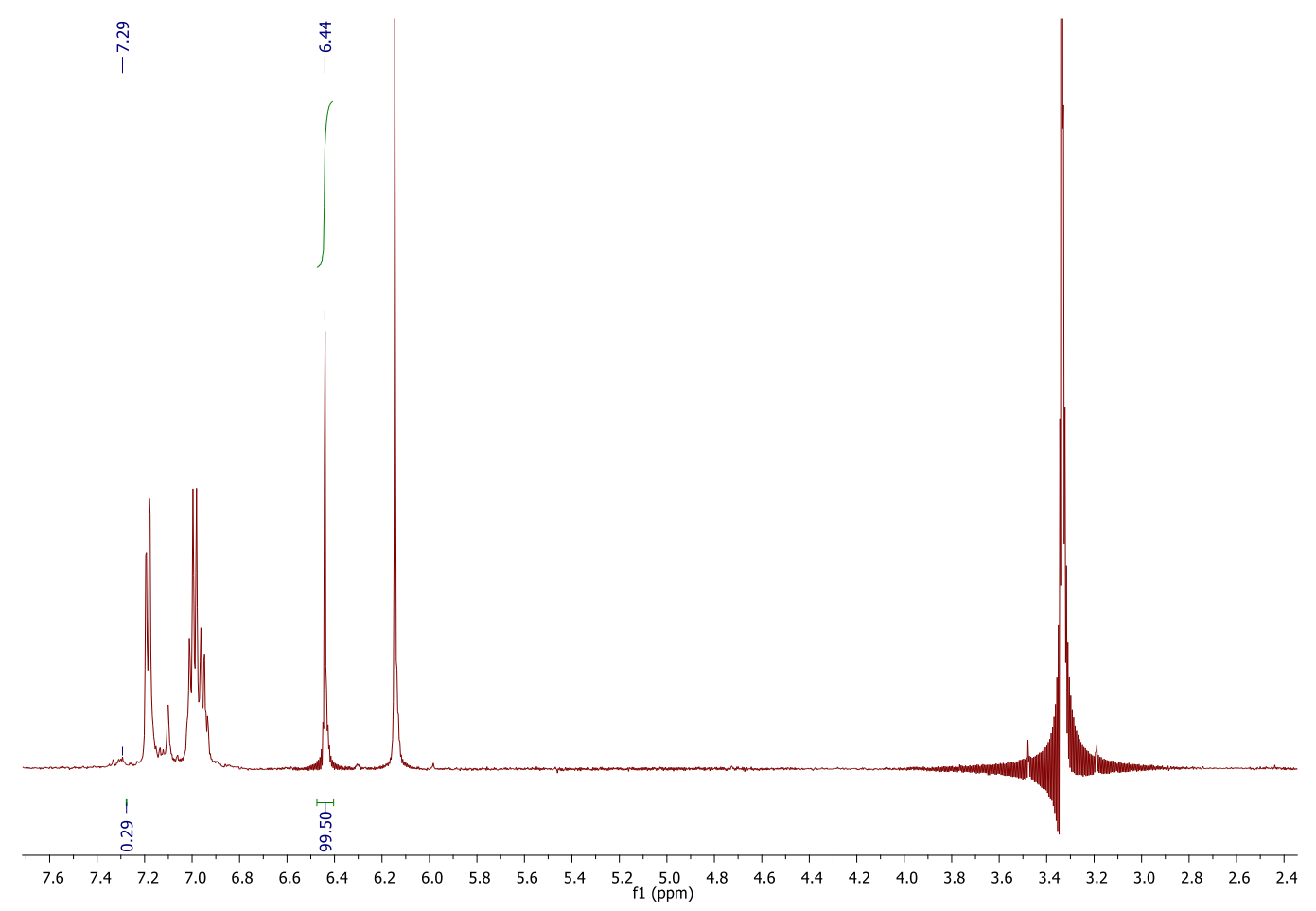

Figure S21: ${ }^{1} \mathrm{H}$ NMR spectrum of cis-stilbene after the reaction under catalytic conditions with the omission of the catalyst only. (Only the peak values and the integrations used to quantify the products have been marked for clarity)

\section{Procedure for the control of the alkene isomerization.}

In a nitrogen filled glovebox, (IMes)Ag-Rp (5.0 mg, 0.2 equiv), cis-stilbene (1 equiv), and an internal standard (hexamethylbenzene or 1,3,5-trimethoxybenzene, 1 equiv) were dissolved in xylenes (1 $\mathrm{mL}$ ), transferred to a J-Young NMR tube, sealed. (The transfer was done in two steps: First, the maximum amount of the solids were dissolved in $0.7 \mathrm{~mL}$ of xylenes and transferred. The vial was washed with another $0.3 \mathrm{~mL}$ of xylenes and the washings were then transferred.) The J-Young tube was inverted multiple times to make sure that all the solids dissolved and then heated in an oil bath at $150{ }^{\circ} \mathrm{C}$ for $24 \mathrm{~h}$. The J-Young tube was then transferred back into the glovebox, and the solution was transferred into a scintillation vial and dried in vacuo. The dried product was then dissolved in toluene- $\mathrm{d}_{8}$ and pipettefiltered through Celite into a J-Young tube. The ${ }^{1} \mathrm{H}-\mathrm{NMR}$ spectrum was recorded. 


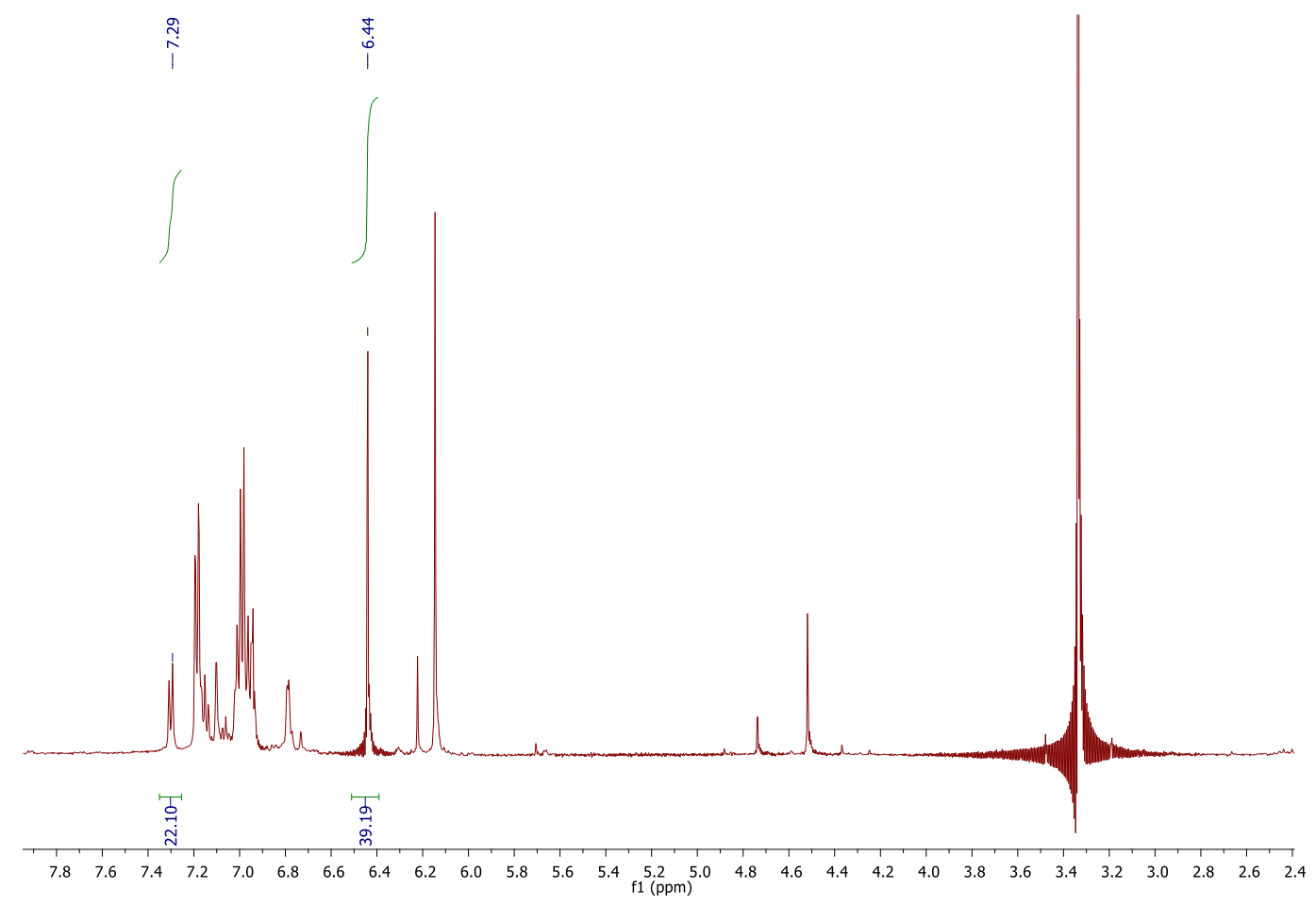

Figure S22: ${ }^{1} \mathrm{H}$ NMR spectrum of $c i s$-stilbene after the reaction under catalytic conditions with the omission of $\mathrm{H}_{2}$ only. (Only the peak values and the integrations used to quantify the products have been marked for clarity)

\section{General procedure for the robustness screen using additives.}

In a nitrogen filled glovebox, (IMes)Ag-Rp (5.0 mg, 0.2 equiv), diphenylacetylene ( 1 equiv), an additive (1 equiv) and an internal standard (hexamethylbenzene or 1,3,5-trimethoxybenzene, 1 equiv) were dissolved in xylenes $(1 \mathrm{~mL})$, transferred to a J-Young NMR tube, and sealed. (The transfer was done in two steps: First, the maximum amount of the solids were dissolved in $0.7 \mathrm{~mL}$ of xylenes and transferred. The vial was washed with another $0.3 \mathrm{~mL}$ of xylenes and the washings were then transferred.) The JYoung tube was inverted multiple times to make sure that all the solids dissolved and then connected to a Schlenk line containing $\mathrm{H}_{2}$ gas (1 atm). After degassing the solution using three 5-minute freeze-pumpthaw cycles, the sample was frozen again, exposed to $\mathrm{H}_{2}$ and allowed to thaw and equilibrate for 30 minutes. The J-Young tube was then resealed and heated in an oil bath at $150{ }^{\circ} \mathrm{C}$ for 6 or $24 \mathrm{~h}$. The JYoung tube was then transferred back into the glovebox, and the solution was transferred into a scintillation vial and dried in vacuo. The dried product was then dissolved in toluene- $\mathrm{d}_{8}$ and pipettefiltered through Celite into a J-Young tube. The ${ }^{1} \mathrm{H}-\mathrm{NMR}$ spectrum was recorded. The spectra for the $24 \mathrm{~h}$ reactions are shown here. 


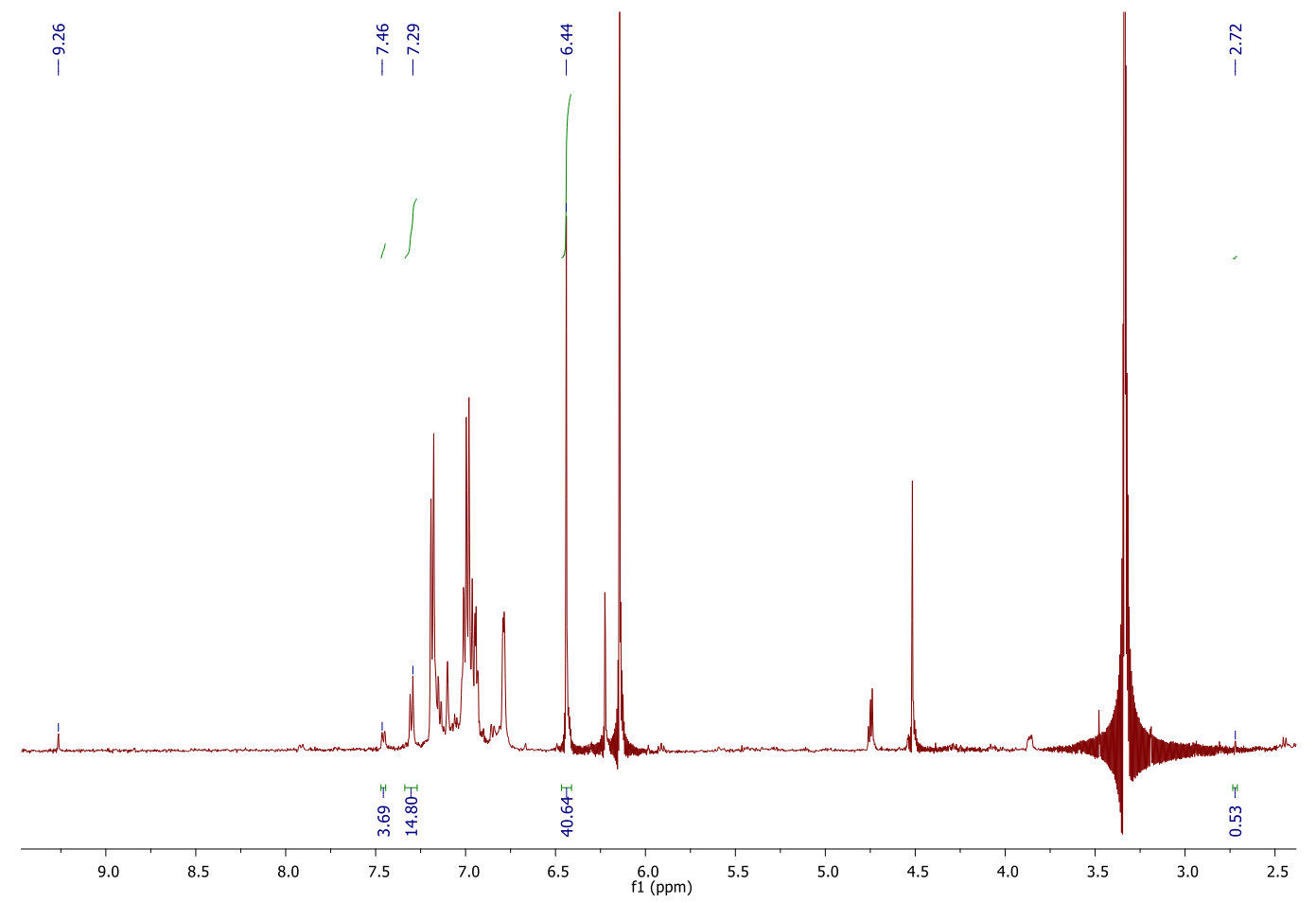

Figure S23: ${ }^{1} \mathrm{H}$ NMR spectrum of the catalytic semi-hydrogenation of diphenylacetylene by (IMes)AgRp with the addition of heptaldehyde (Only the peak values and the integrations used to quantify the products and the aldehyde peak have been marked for clarity) 


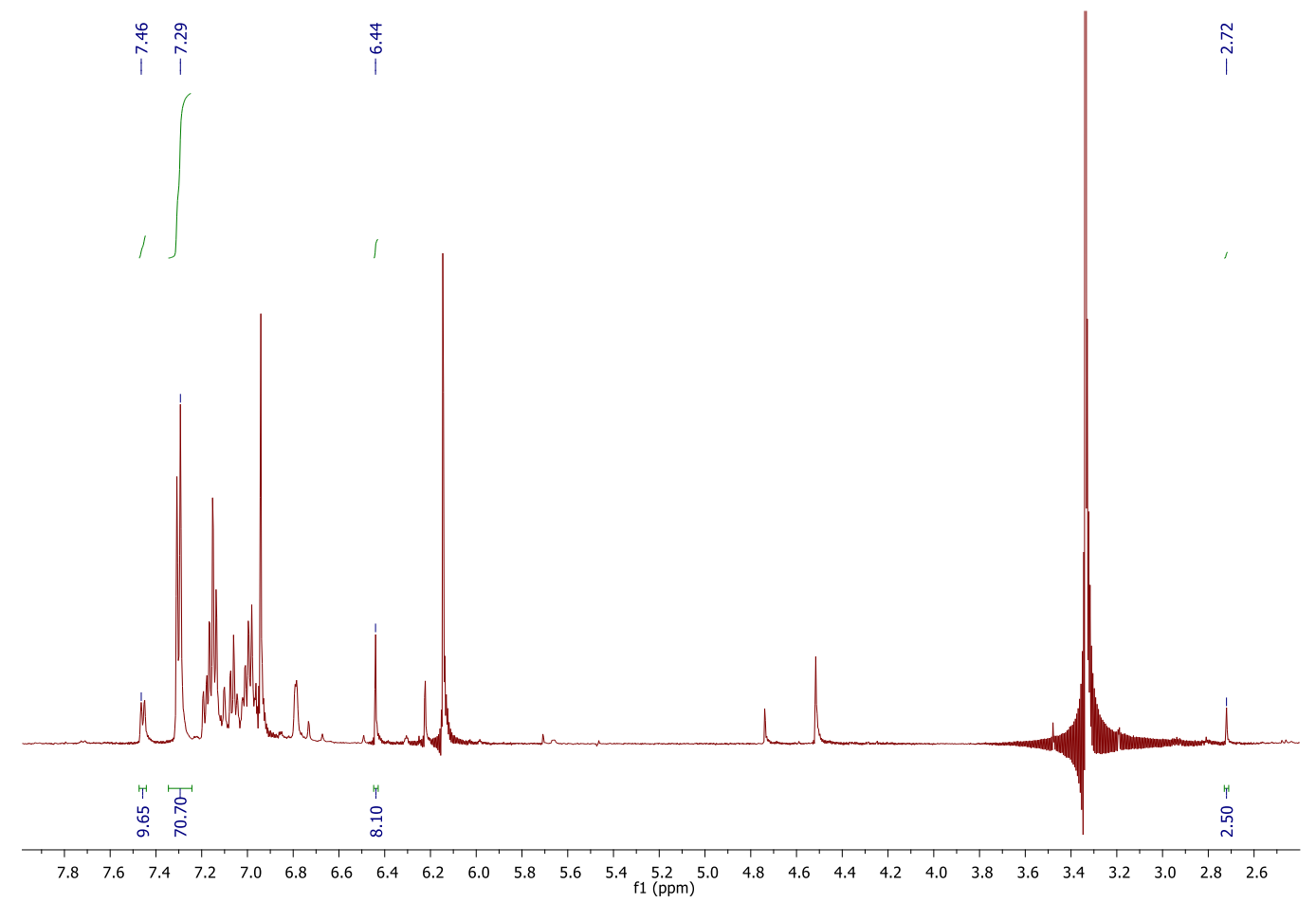

Figure S24: ${ }^{1} \mathrm{H}$ NMR spectrum of the catalytic semi-hydrogenation of diphenylacetylene by (IMes)AgRp with the addition of 6-Undecanone (Only the peak values and the integrations used to quantify the products have been marked for clarity) 


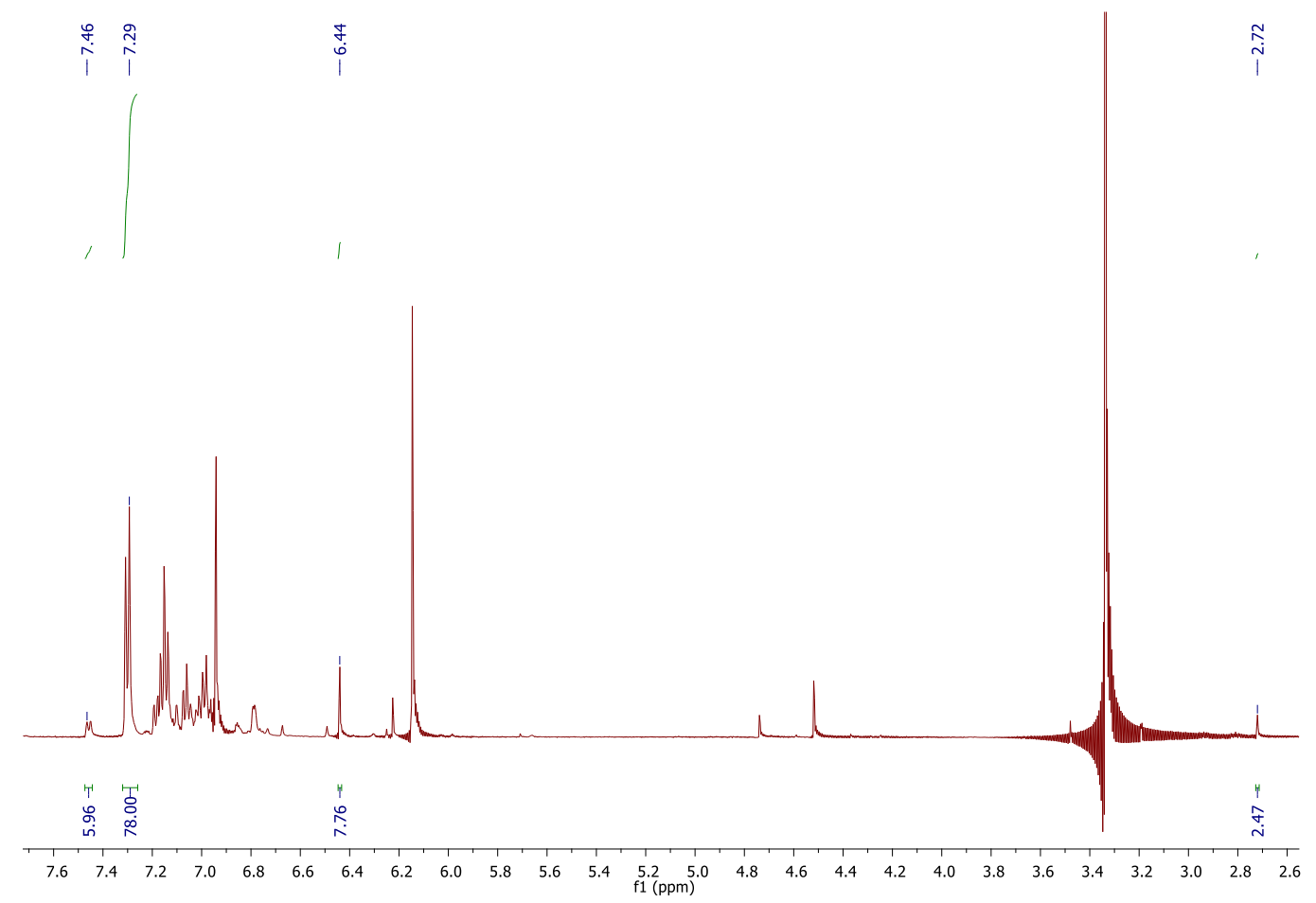

Figure S25: ${ }^{1} \mathrm{H}$ NMR spectrum of the catalytic semi-hydrogenation of diphenylacetylene by (IMes)AgRp with the addition of acetonitrile (Only the peak values and the integrations used to quantify the products have been marked for clarity) 


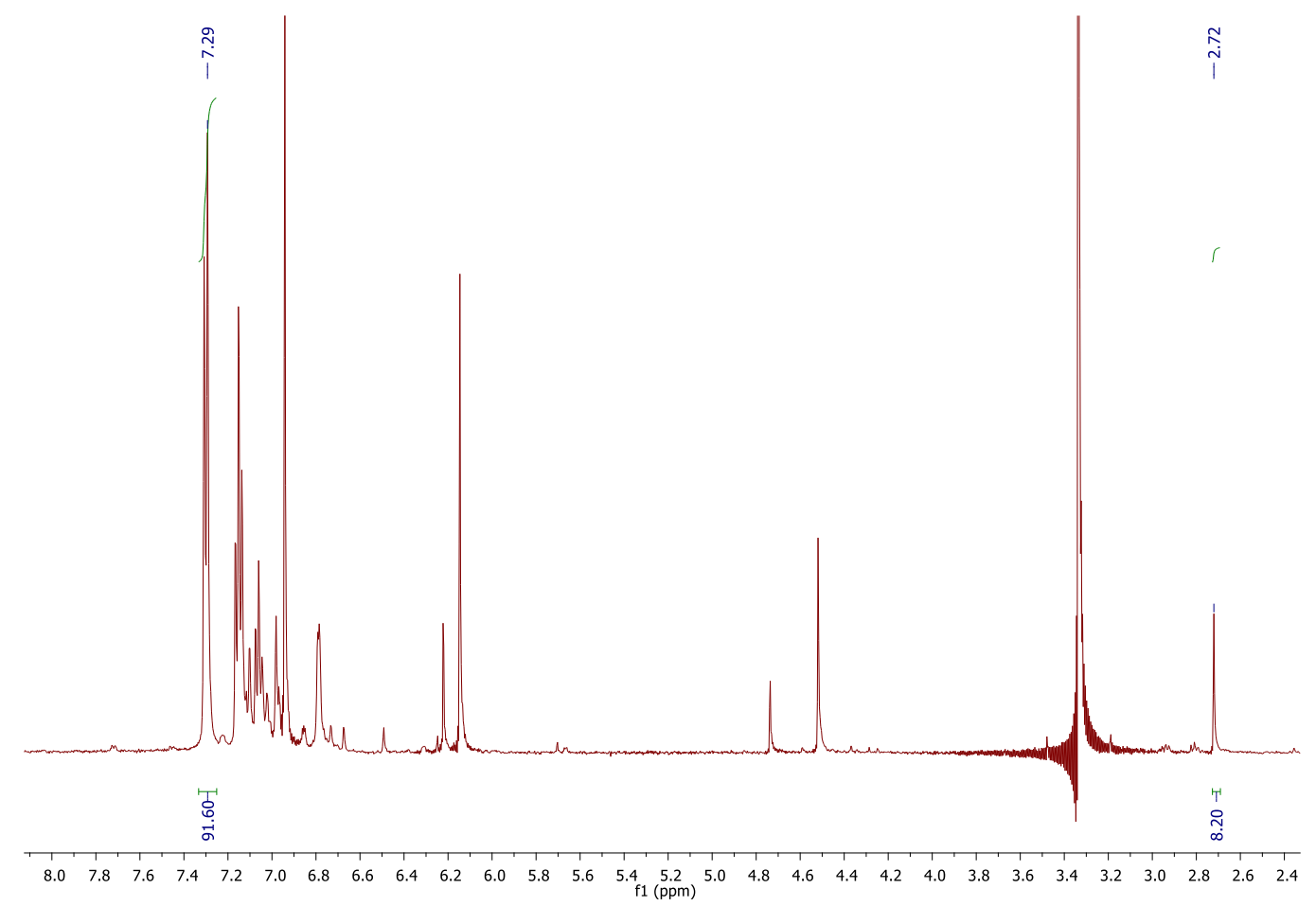

Figure S26: ${ }^{1} \mathrm{H}$ NMR spectrum of the catalytic semi-hydrogenation of diphenylacetylene by (IMes)AgRp with the addition of ethyl acetate (Only the peak values and the integrations used to quantify the products have been marked for clarity) 


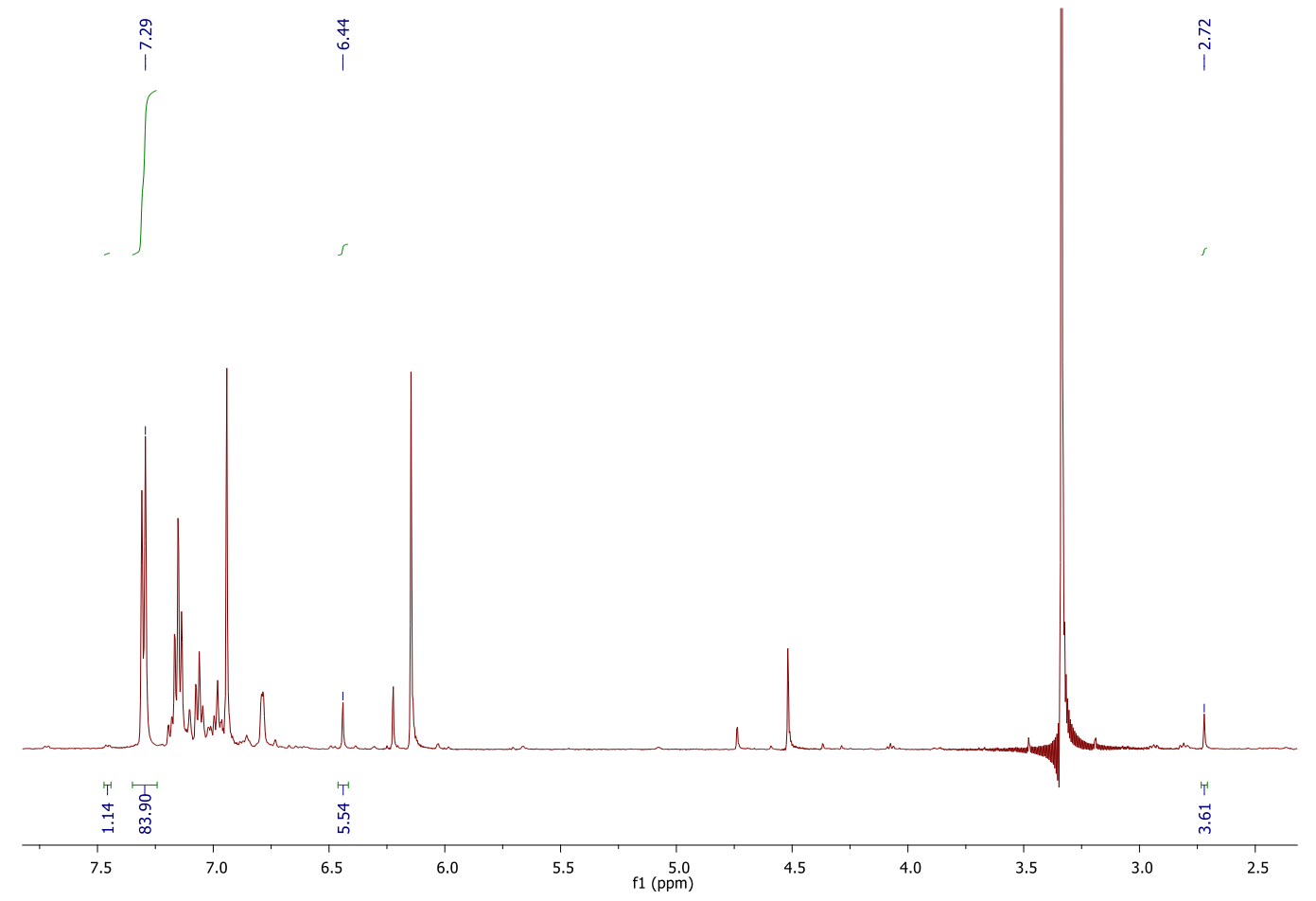

Figure S27: ${ }^{1} \mathrm{H}$ NMR spectrum of the catalytic semi-hydrogenation of diphenylacetylene by (IMes)AgRp with the addition of 1-butanol (Only the peak values and the integrations used to quantify the products have been marked for clarity) 


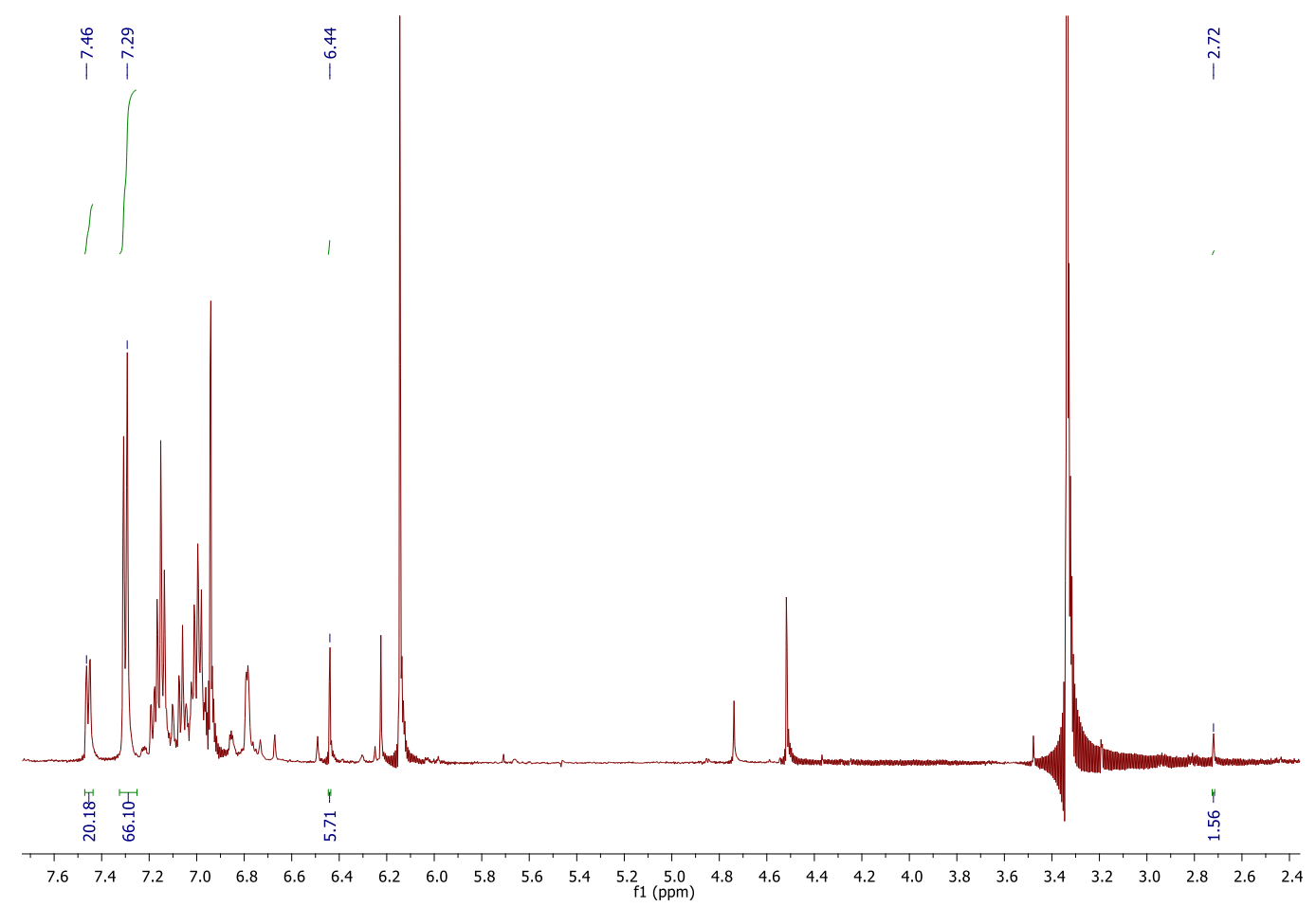

Figure S28: ${ }^{1} \mathrm{H}$ NMR spectrum of the catalytic semi-hydrogenation of diphenylacetylene by (IMes)AgRp with the addition of pyridine (Only the peak values and the integrations used to quantify the products have been marked for clarity) 


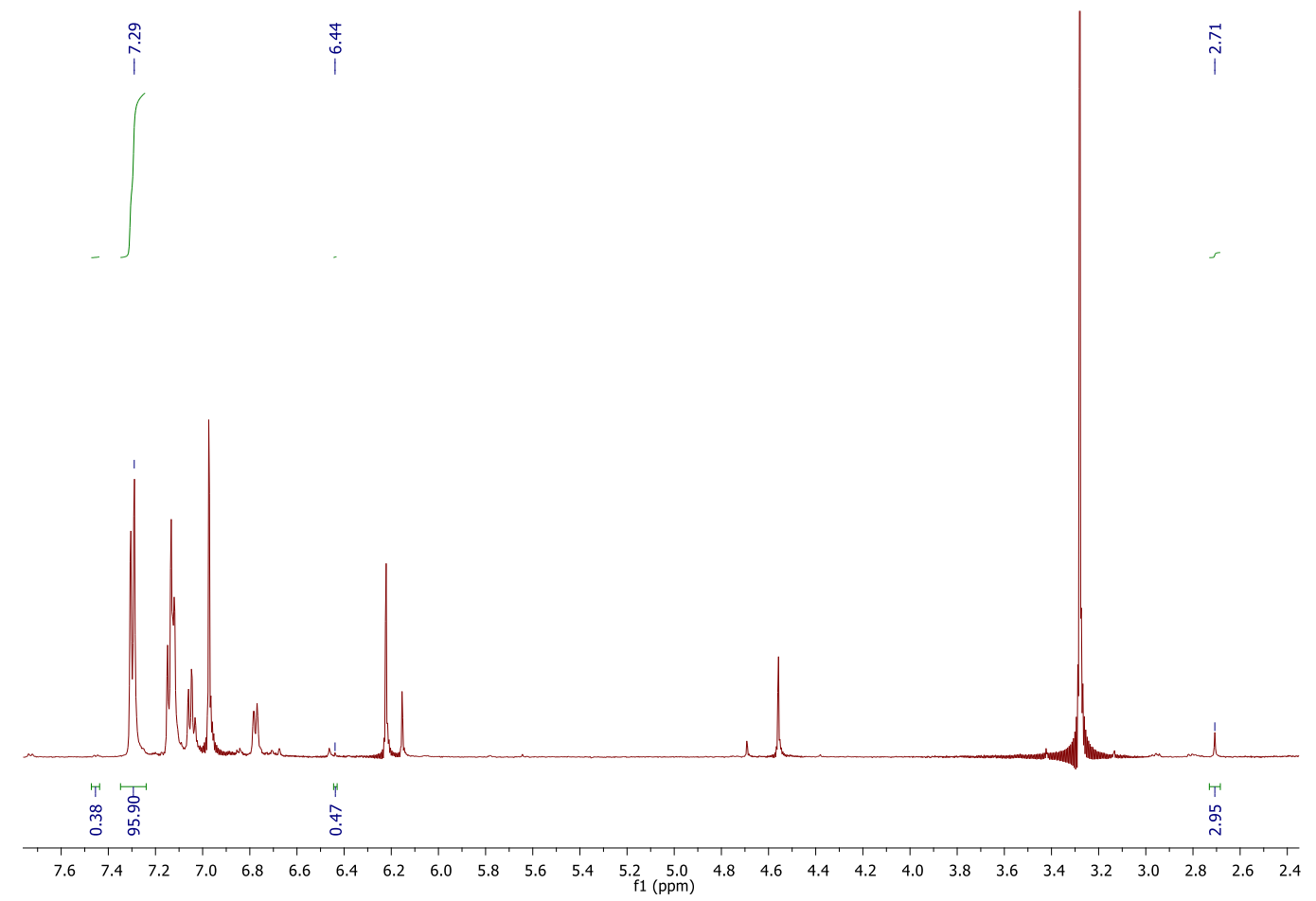

Figure S29: ${ }^{1} \mathrm{H}$ NMR spectrum of the catalytic semi-hydrogenation of diphenylacetylene by (IMes)AgRp with the addition of 1-dodecene (Only the peak values and the integrations used to quantify the products have been marked for clarity) 


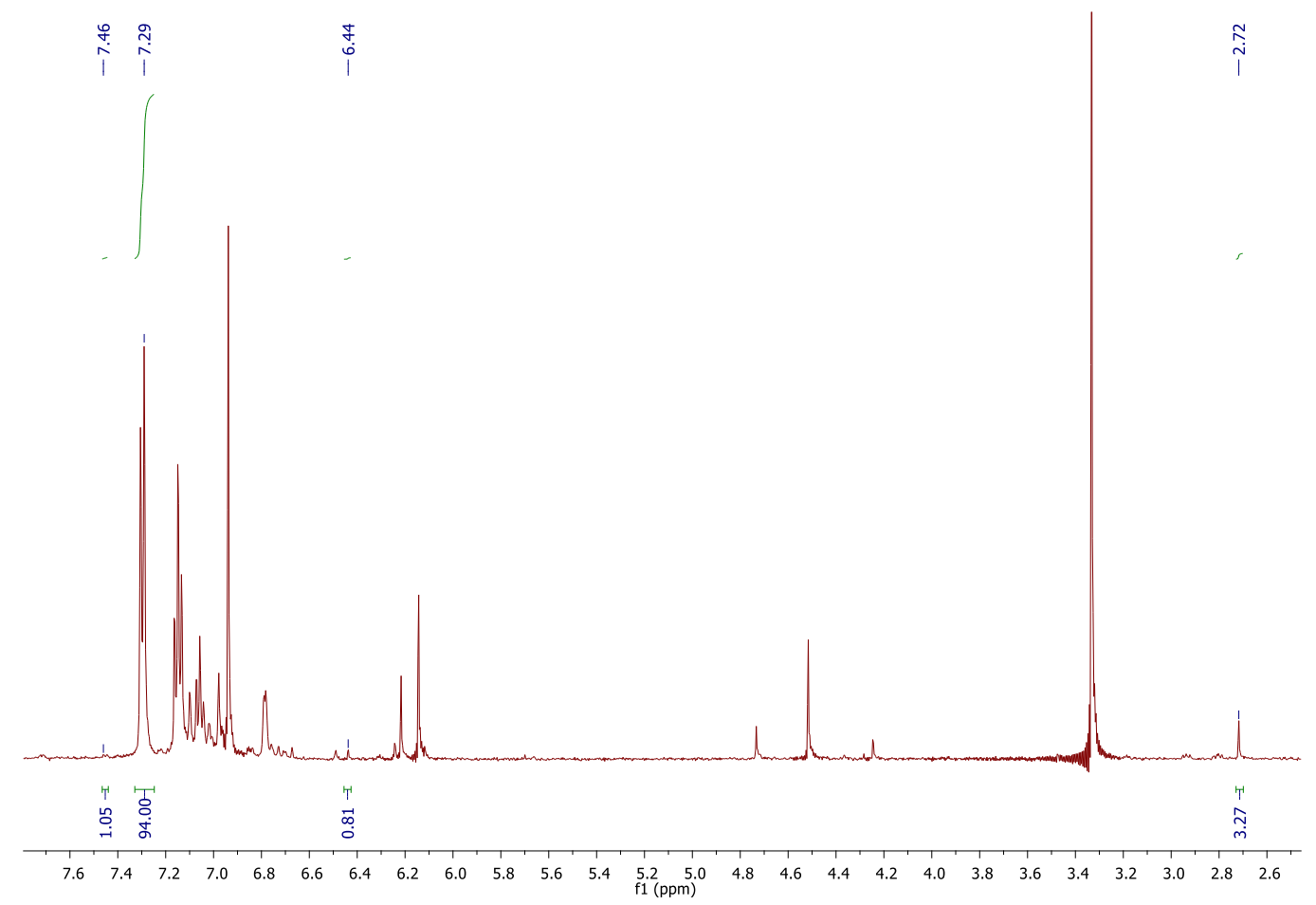

Figure S30: ${ }^{1} \mathrm{H}$ NMR spectrum of the catalytic semi-hydrogenation of diphenylacetylene by (IMes)AgRp with the addition of neopentyl chloride (Only the peak values and the integrations used to quantify the products have been marked for clarity) 
${ }^{1}$ Kalz, K. F.; Kindermann, N.; Xiang, S.-Q.; Kronz, A.; Lange, A.; Meyer, F. Organometallics 2014, 33 , 1475-1479.

${ }^{2}$ Partyka, D. V.; Deligonul, N. Inorg. Chem. 2009, 48, 9463-9475.

${ }^{3}$ de Fremont, P.; Scott, N. M.; Stevens, E. D.; Ramnial, T.; Lightbody, O. C.; Macdonald, C. L. B.; Clyburne, J. A. C.; Abernethy, C. D.; Nolan, S. P. Organometallics 2005, 24, 6301-6309.

${ }^{4}$ Ohishi, T.; Shiotani, Y.; Yamashita, M. J. Org. Chem. 1994, 59, 250-250.

${ }^{5}$ Banerjee, S.; Karunananda, M. K.; Bagherzadeh, S.; Jayarathne, U.; Parmelee, S. R.; Waldhart, G. W.; Mankad, N. P. Inorg. Chem. 2014, 53, 11307-11315.

${ }^{6}$ Sheldrick, G. M. Acta Crystallogr., Sect. A: Found. Crystallogr. 2008, 64, 112-122.

${ }^{7}$ Müller, P. Crystallogr. Rev. 2009, 15, 57-83.

${ }^{8}$ Jayarathne, U.; Mazzacano, T. J.; Bagherzadeh, S.; Mankad, N. P. Organometallics 2013, 32, 3986-3992

${ }^{9}$ Frisch, M. J.; Trucks, G. W.; Schlegel, H. B.; Scuseria, G. E.; Robb, M. A.; Cheeseman, J. R.; Scalmani, G.; Barone, V.; Mennucci, B.; Petersson, G. A.; Nakatsuji, H.; Caricato, M.; Li, X.; Hratchian, H. P.; Izmaylov, A. F.; Bloino, J.; Zheng, G.; Sonnenberg, J. L.; Hada, M.; Ehara, M.; Toyota, K.; Fukuda, R.; Hasegawa, J.; Ishida, M.; Nakajima, T.; Honda, Y.; Kitao, O.; Nakai, H.; Vreven, T.; Montgomery, J. A., Jr., Peralta, J. E.; Ogliaro, F.; Bearpark, M.; Heyd, J. J.; Brothers, E.; Kudin, K. N.; Staroverov, V. N.; Keith, T.; Kobayashi, R.; Normand, J.; Raghavachari, K.; Rendell, A.; Burant, J. C.; Iyengar, S. S.; Tomasi, J.; Cossi, M.; Rega, N.; Millam, J. M.; Klene, M.; Knox, J. E.; Cross, J. B.; Bakken, V.; Adamo, C.; Jaramillo, J.; Gomperts, R.; Stratmann, R. E.; Yazyev, O.; Austin, A. J.; Cammi, R.; Pomelli, C.; Ochterski, J. W.; Martin, R. L.; Morokuma, K.; Zakrzewski, V. G.; Voth, G. A.; Salvador, P.; Dannenberg, J. J.; Dapprich, S.; Daniels, A. D.; Farkas, O.; Foresman, J. B.; Ortiz, J. V.; Cioslowski, J.;, Fox, D. J. Gaussian 09, Revision B.01; Gaussian, Inc.: Wallingford, CT, 2010

${ }^{10}$ Becke, A. D. Phys. Rev. A: At., Mol., Opt. Phys. 1988, 38, 3098.

${ }^{11}$ Perdew, J. Phys. Rev. B: Condens. Matter Mater. Phys. 1986, 33, 8822-8824.

${ }^{12}$ Hay, P. J.; Wadt, W. R. J. Chem. Phys. 1985, 82, 299-13.

${ }^{13}$ Roy, L. E.; Hay, P. J.; Martin, R. L. J. Chem. Theory Comput. 2008, 4, 1029-1031.

${ }^{14}$ Ehlers, A. W.; Böhme, M.; Dapprich, S.; Gobbi, A.; Höllwarth, A.; Jonas, V.; Kö hler, K. F.; Stegmann, R.; Veldkamp, A.; Frenking, G. Chem. Phys. Lett. 1993, 208, 111-114.

${ }^{15}$ Hay, P. J.; Wadt, W. R. J. Chem. Phys. 1985, 82, 270

${ }^{16}$ Wadt, W. R.; Hay, P. J. J. Chem. Phys. 1985, 82, 284-16.

${ }^{17}$ Yamada, Y. M. A.; Yuyama, Y.; Sato, T.; Fujikawa, S. and Uozumi, Y. Angw. Chem. Int. Ed. 2014, 53, $127-131$.

${ }^{18}$ Mio, M. J.; Kopel, L. C.; Braun, J. B.; Gadzikwa, T. L.; Hull, K. L.; Brisbois, R. G.; Markworth, C. J.; Grieco, P. A. Org. Lett., 2002, 4, 3199-3202

${ }^{19}$ Tanaka, S.; Itami, K.; Sunahara, K.; Tatsuta, G. and Mori, A. Chem. Commun., 2015, 51, 1949-1952

${ }^{20}$ Tai, C.-C.; Yu, M.-S.; Chen, Y.-L.; Chuang, W.-H.; Lin, T.-H.; Yap, G. P. a.; Ong, T.- G. Chem. Commun. 2014 , $50,4344-4346$

${ }^{21}$ Manley, D. W.; Walton, J. C.; Org. Lett., 2014, 16, 5394-5397

${ }^{22}$ Mio, M. J.; Kopel, L. C.; Braun, J. B.; Gadzikwa, T. L.; Hull, K. L.; Brisbois, R. G.; Markworth, C. J.; Grieco, P. A. Org. Lett., 2002, 4, 3199-3202

${ }^{23}$ Nojima, M.; Ohta, Y.; Yokozawa, T. J. Am. Chem. Soc. 2015, 137, 5682-5685

${ }^{24}$ Belluci, G.; Bianchini, R.; Chiappe, C.; Brown, R. S. and Slebocka-Tilk, H. J. Am. Chem. Soc. 1991, $113,8012-$ 8016

${ }^{25}$ Manley, D. W.; Walton, J. C.; Org. Lett., 2014, 16, 5394-5397

${ }^{26}$ Feng, Y.-S.; Xie, C.-Q.; Qiao, W. L.; Xu, H. J. Org. Lett. 2013, 15, 936.

${ }^{27}$ Fah, C.; Mathys, R.; Hardegger, L. A.; Mayer, S.; Bur, D. and Diederich, F. Eur. J. Org. Chem. 2010, $24,4617-$ 4629. 